\title{
Improving the solar carbothermal reduction of magnesia for metallic fuels production through reactor designing, milling and binders
}

\author{
Youssef Berro, Romain Masse, Jean Puig, Marianne Balat-Pichelin* \\ Laboratoire PROcédés, Matériaux et Energie Solaire, PROMES-CNRS, UPR 8521, 7 rue du four solaire, 66120 \\ Font-Romeu-Odeillo, France. \\ *corresponding author: marianne.balat@promes.cnrs.fr
}

\begin{abstract}
The production of magnesium particles through the carbothermal reduction of magnesia using concentrated solar energy has engaged the attention of researchers as a sustainable production process. This process allows the effective employ of those particles as recyclable combustion metal fuels for terrestrial transportation having high energetic value with zero greenhouse gas emissions. Herein, we investigated the improvement of this production process, at low pressures, by designing the Sol@rmet reactor and using various catalysts. Simulations and experiments are performed to determine the parameters (inlets and flow rates) allowing a gas circulation in the reactor favoring the production of metallic magnesium powders. Modeling results were confirmed by experiments showing that a double argon entry creates a favorable swirl circulation, thus increasing the Mg yield from 52 to $68 \%$. A further improvement, to reach around $85 \%$, is attained by the mechanical milling the $\mathrm{C} / \mathrm{MgO}$ powders. Additionally, we inspected the effect of binders and metallic catalysts (iron and nickel) on the reaction conversion and kinetics. Solar experiments proved that bentonite binder has a catalytic-like behavior allowing to reach values up to $95 \%$ of $\mathrm{Mg}$ yield and purity.
\end{abstract}

Keywords: carbothermal reduction; solar fuels; catalyst; reactor design; bentonite binder. 


\section{Introduction}

In the last decades, researchers focused on developing new technologies to benefit from renewable energy sources and to confront fossil fuel depletion and global warming (Hoel and Kverndokk, 1996). It has been found, according to a System Dynamics Energy-EconomyEnvironment model, that transportation is the most critical sector (Capellán-Pérez et al., 2014), accounting for around 28\%, in 2010, of the global greenhouse gases (GHGs) emissions in France (Dussud et al., 2015). Thus, the development of environmental-friendly cars and the use of sustainable clean fuels becomes a crucial subject to investigate.

Recently, an innovative process based on the direct combustion of metal fuels in a metalfueled combustor is proposed with the ability to collect the combustion oxide products and regenerate the metallic fuels using renewable sources (Bergthorson et al., 2015). The new design of metal-fueled engines for cars, illustrated in Figure 1, allows the combustion of metal fuels in a burner under a stable flame, the improvement of the burning time and the efficient collection of oxides (Lomba et al., 2015). They proved that the combustion occured following a vapor-phase reaction at lower flame temperatures for finer metal particles (Lomba et al., 2016). Using this new metal combustor, similar $\mathrm{NO}_{\mathrm{x}}$ emissions were produced as for conventional internal combustion engines (Laraqui et al., 2019). Moreover, an optimal heat-to-mechanical conversion efficiency of $80 \%$ is achieved in the power generation system where 50-70 $\mu \mathrm{m}$ magnesium particles are combusted in a swirled-stabilized metal-air burner and $98 \%$ of the produced submicron magnesia particles are trapped and collected (Laraqui et al., 2020).

The regeneration of the metallic $\mathrm{Mg}$ fuels through the carbothermal reduction of magnesia, under low vacuum conditions, using concentrated solar energy proved to be an efficient environmentally-friendly technology (Puig and Balat-Pichelin, 2017). In fact, when using carbon as a reducing agent, the reduction becomes easier and the equilibrium 
temperature of the reaction decreases from 3700 to $2130 \mathrm{~K}$ (Steinfeld and Palumbo, 2003). Moreover, operating under vacuum when using renewable solar energy is advantageous as it reduces the reduction temperature with low exergy cost (Balomenos et al., 2012). Thermodynamic studies proved that lowering the operating pressure improves the reduction rate and decreases the onset temperature of the reaction from $1800 \mathrm{~K}$ under $\mathrm{P}_{\text {atm }}$ to $1300 \mathrm{~K}$ under $10 \mathrm{~Pa}$ (Puig and Balat-Pichelin, 2016). Solar experiments, performed using the Sol@rmet reactor under $900 \mathrm{~Pa}$, highlighted that a $\mathrm{C} / \mathrm{MgO}$ molar ratio of 1.25 is sufficient for the reaction, showing similar performance as for higher ratios. Those experiments also demonstrated that biochar is a better reductant than black carbon, giving a Mg yield of around $50 \%$ with $97 \%$ product purity, around 5\% higher than that of black carbon (Puig and BalatPichelin, 2018). Furthermore, a slow preheating will decrease the starting and average temperatures of the reaction, which will necessitate longer reaction times leading to $\mathrm{MgO}$ sintering and loss of $\mathrm{C} / \mathrm{MgO}$ contact. Hence, the use of concentrated solar energy is advantageous as high temperatures can be rapidly reached (Vishnevetsky and Epstein, 2015; Vishnevetsky, 2016). However, once the reaction begins, a gradual increase of the temperature improves the reaction rate and the metal yield (Puig and Balat-Pichelin, 2018).

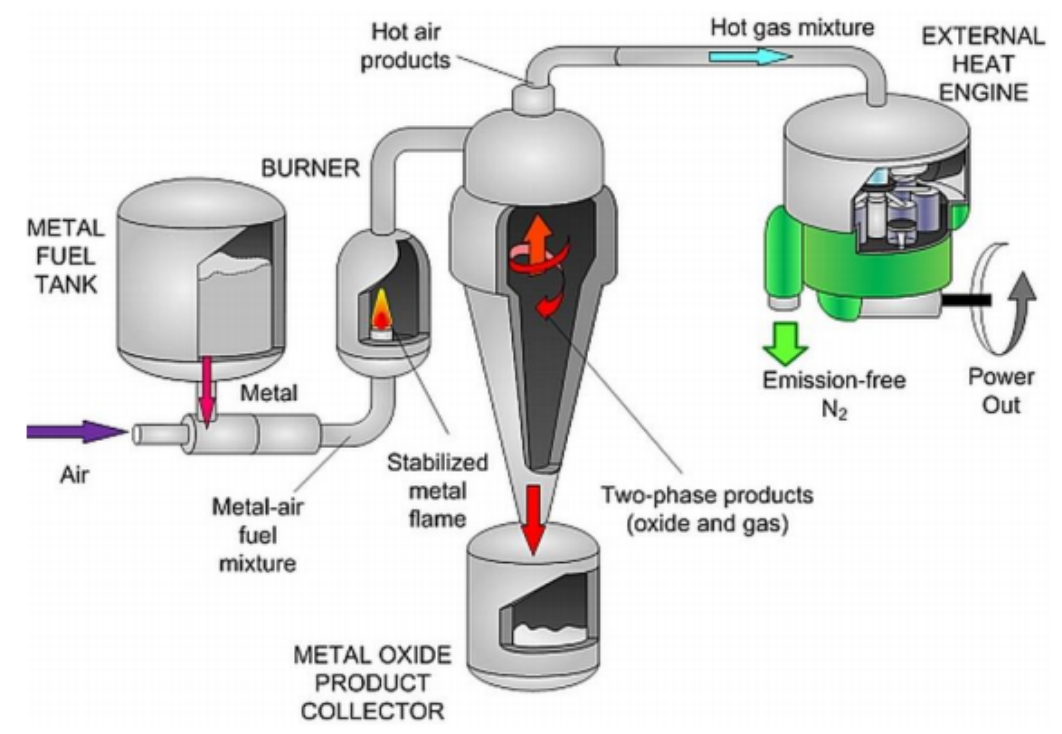

Figure 1. Schematic of a metal-fueled combustor for clean sustainable energy production (Laboureur et al., 2018). 
To enhance the reduction rate and increase the magnesium yield, one must understand the reaction kinetics that depends highly on the reaction pressure. In fact, when the pressure increases, the reaction stoichiometry $\lambda$ (see reaction 1 and equation 1 ) decreases, thus more $\mathrm{CO}_{2}$ is produced which promotes the gasification (Boudouard reaction) and gas diffusion $\left(\mathrm{MgO} / \mathrm{CO}\right.$ reaction). The activation energy rises from around $200 \mathrm{~kJ} \cdot \mathrm{mol}^{-1}$ at $100-1000 \mathrm{~Pa}$ (phase boundary reaction) to $325 \mathrm{~kJ} \cdot \mathrm{mol}^{-1}$ at $10^{4}-10^{5} \mathrm{~Pa}$, meaning that the rate-limiting has changed as the influence of the gas-solid reactions is more important at higher pressures (Chubukov et al., 2016). Similarly, Xiong et al. (Xiong et al., 2019) concluded that, under vacuum, the CO partial pressure is reduced which promotes the solid-solid interface reaction. Thus, the removal of the produced $\mathrm{CO}$, through efficient gas circulation, will accelerate the reaction rate. This necessitates inspecting the effect of the carrier gas circulation in the reactor to eliminate the produced $\mathrm{CO}$.

The chemical reaction can be written as follows:

$$
\begin{aligned}
& M g O_{x}+\lambda C \leftrightarrow M g O_{(x-1)}+(2 \lambda-1) C O+(1-\lambda) C O_{2} \\
& \text { Where } \lambda={ }^{\left(N_{C i}-N_{C f}\right) /\left(N_{M g O i}-N_{M g O f}\right)}
\end{aligned}
$$

Historically, numerical calculations were performed to upgrade the design of the solar reactors, used for the solar reduction of oxides, aiming to improve the set-up efficiency. The spherical and cylindrical geometrical designs of solar reactors, first proposed by Murray et al. (Murray et al., 1995), were modeled via computational fluid dynamics (CFD) using ANSYS FLUENT proving that the spherical shape is more adapted allowing a more homogeneous and uniform temperature distribution in the reactor (Costandy et al., 2012). Moreover, optical analysis confirmed that the spherical geometry provides more ray scattering due to the 
continuously curving geometry, with less optical reflection losses, resulting in higher temperatures (Costandy et al., 2012). Similar simulations, performed using ELMER and FLUENT models, motivate the design of a new solar reactor (having a semi-spherical quartz dome) for alumina carbothermal reduction under vacuum, allowing to reach higher temperatures while preventing the backward reaction (Ben-Zvi, 2013). Experiments have validated the performance of this new design giving alumina to aluminum conversion higher than $90 \%$ (Vishnevetsky et al., 2014).

Mechanical milling is considered a good solution, to confront the sintering of magnesia and the loss of the $\mathrm{C} / \mathrm{MgO}$ contact, as it decreases the size of $\mathrm{MgO}$ particles and increases the specific surface area of the $\mathrm{C} / \mathrm{MgO}$ sample which allows rising the reactants weight loss from $24 \%$ without milling to $40,51,58$, and $68 \%$ when milled for $1,2,4$, and 8 hours respectively (Nusheh et al., 2010). Similar results were obtained during the reduction of $\mathrm{MgO}$, at $1823 \mathrm{~K}$ under $10^{4} \mathrm{~Pa}$, when milled with petroleum coke where $90 \%$ conversion is reached after 30 min without milling, while it reached the same value after 15 or 5 min when milled for 30 or 120 min respectively (Chubukov et al., 2017). Moreover, during the magnesia carbothermal reduction at atmospheric pressure, metallic catalysts $(\mathrm{Cu}, \mathrm{Co}, \mathrm{Ni}$ and $\mathrm{Fe})$ accelerate the reaction rate at temperatures higher than $1600 \mathrm{~K}$ (catalytic activity scale: $\mathrm{Ni}>\mathrm{Cu}>\mathrm{Co}$ ), in addition only Fe decreases the starting temperature of the reaction to $1400 \mathrm{~K}$ instead of 1600 K (Rongti et al., 2003). Whereas, the catalytic effect of metal-based catalysts is not evident at lower pressures $(0.1 \mathrm{kPa})$ as the phase boundary reaction dominates while at high pressure, the gas-solid reaction is more probable to occur and could be catalyzed (Chubukov et al., 2017). However, calcium fluoride binder proved to have a catalytic effect during the carbothermal reduction of magnesia at $1723 \mathrm{~K}$ under $30-100 \mathrm{~Pa}$, as the reduction extent increases from 45 to $72 \%$ with $1 \% \mathrm{CaF}_{2}$ (Tian et al., 2012). Organic (starch and molasses) and inorganic (bentonite and lime) binders were used and pellets with 5\% bentonite-5\% 
starch showed the best mechanical strength where the bentonite conserves the strength under heat while the starch is decomposed into char which might be profitable for the reduction (Chubukov et al., 2018).

Motivated by those prior findings, this study aims to improve the performance of the carbothermal reduction of magnesia under a low vacuum, using concentrated solar energy, to increase the production of magnesium fuel powders. Simulations and experiments for reactor designing allow attaining a swirl gas circulation, thus eliminating the produced $\mathrm{CO}$ and increasing the reaction extent. More important, solar experiments comparing the effect of milling, binders, and metallic catalysts (iron or nickel) proved that milling is advantageous and that bentonite binder has a catalytic role giving 95\% $\mathrm{Mg}$ yield and purity.

\section{Experimental Set-up}

Magnesia reduction experiments are performed in the Sol@rmet reactor, using a concentrated solar power of around 15000 suns $\left(15 \mathrm{x} 10^{6} \mathrm{~W} \cdot \mathrm{m}^{-2}\right)$ generated by a $1.5 \mathrm{~kW}$ solar furnace, when the direct normal irradiation (DNI) is higher than $900 \mathrm{~W} \cdot \mathrm{m}^{-2}$ (change less than 3\% during each experiment). The Sol@rmet reactor, showed in Figure 2, consists of a cooled metallic part and a glass dome allowing the passage of the solar radiation, with various gas inlets and outlets. A dry primary pump (Edwards nXDS15i), having a maximum pumping rate of $15 \mathrm{~m}^{3} \cdot \mathrm{h}^{-1}$, permits to regulate the reactor pressure by controlling the carrier gas (argon) flow rate. The progressive opening of the shutter, placed between the heliostat and the parabolic mirror, enables the gradual increase of the reaction temperature. An optical monochromatic pyrometer (Heitronics K15.42 II, $5 \mu \mathrm{m}$ ) is used to measure the temperature of the $\mathrm{C} / \mathrm{MgO}$ pellet supposing that its emissivity is 0.95 at this wavelength. However, modeling

results showed that the measured temperature is around 100-200 $\mathrm{K}$ higher than the real temperature at the pellet surface (Puig and Balat-Pichelin, 2018). 


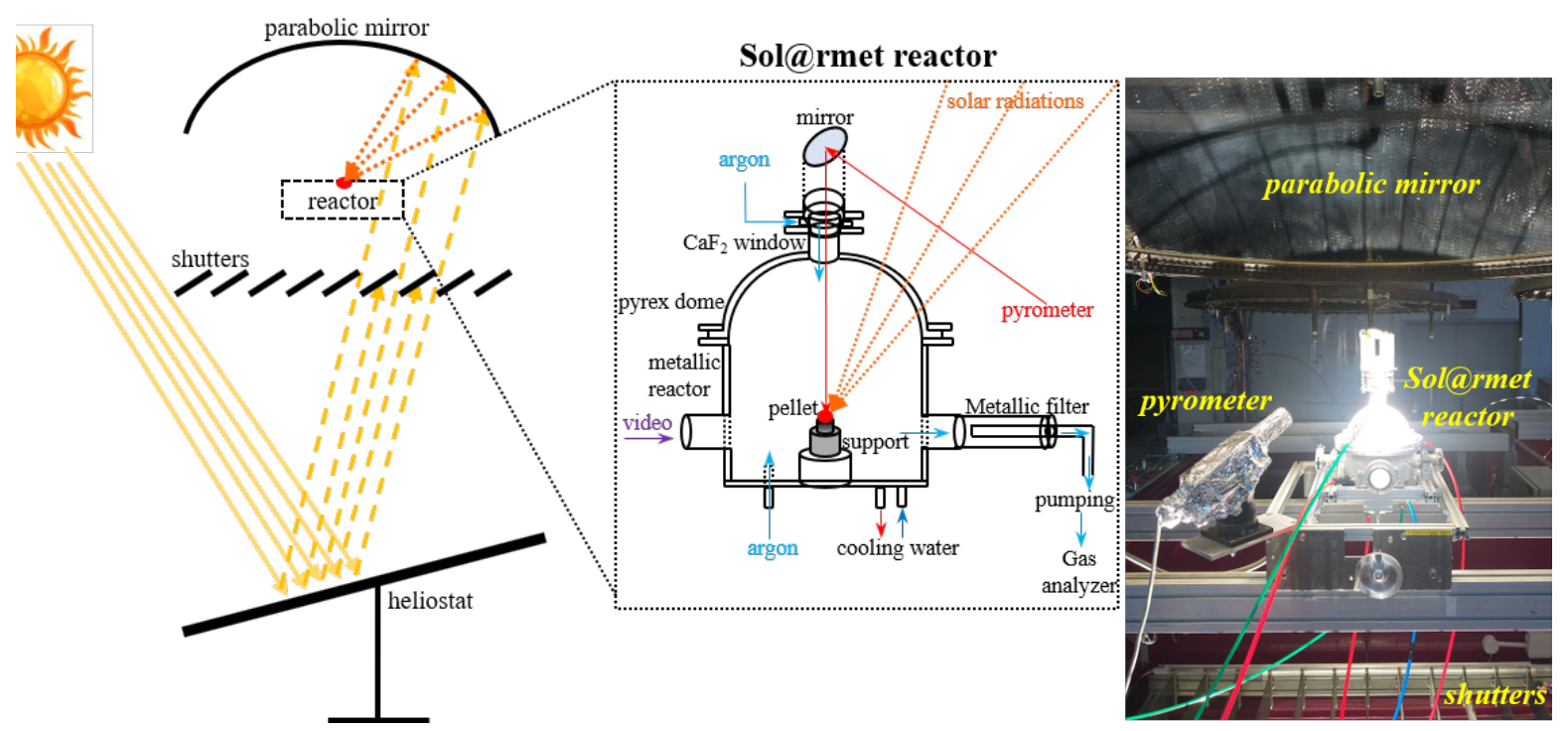

Figure 2. Experimental set-up and photo of the concentrating solar system and the Sol@rmet reactor.

Pure magnesia (Sigma-Aldrich, $>99 \%, \varnothing<44 \mu \mathrm{m})$ and carbon are milled $(\mathrm{C} / \mathrm{MgO}$ molar ratio of 1.25) with various binders as polyvinyl alcohol (PVA), bentonite, and starch manually or mechanically using Fritsch Pulverisette 4 mill. Two types of carbon reductants are used, the purchased birch charcoal (Carbon Terra, pyrolysis at $770 \mathrm{~K}$ for 4 hours, $\varnothing<12$ $\mu \mathrm{m})$ and the chimney charcoal (obtained from a house chimney). Cylindrical pellets $(\varnothing=8$ $\mathrm{mm}$, thickness $=2-3 \mathrm{~mm}$ ) are formed by dry pressing of the milled powders at one ton. Iron (Sigma-Aldrich, 97\%, $\varnothing<44 \mu \mathrm{m}$ ) and nickel (Sigma-Aldrich, Raney) catalysts are added at various percentages to some of the $\mathrm{C} / \mathrm{MgO}$ pellets.

A porous stainless-steel filter (98\% retention of $0.2 \mu \mathrm{m}$ particles) placed on the entry of the pumping tube allows collecting the produced powders, while the produced $\mathrm{CO}$ and $\mathrm{CO}_{2}$ are analyzed during the reaction using the Xstream X2GP infrared gas analyzer (Emerson). A small quantity of powders is condensed on the reactor walls before reaching the surface. The collected powders are analyzed by X-ray diffraction (PANalytical X'Pert Pro) and the approximate percentages of $\mathrm{Mg}$ and $\mathrm{MgO}$ are quantified using Highscore Plus software (comparing to International Centre for Diffraction Data ICDD files using reference intensity 
ratio technique). The morphology and size of the metal powders are determined by granulometric analysis (Malvern Mastersizer 3000) and Scanning Electron Microscopy.

The performance of the magnesia reduction is determined by computing the magnesium metallic yield $\left(y_{M g}\right)$ according to equation (2), where $m_{M g m a x}$ is the maximum quantity of $\mathrm{Mg}$ that can be produced based on the initial magnesia molar quantity, $\% M g_{\text {filter }}$ and $\% M g_{\text {reactor }}$ are the percentages of $\mathrm{Mg}$, determined by $\mathrm{XRD}$, in the collected powders from the filter and the reactor walls respectively:

$y_{M g}(\%)=100 *\left(m_{\text {filter }} * \% M g_{\text {filter }}+m_{\text {reactor }} * \% M g_{\text {reactor }}\right) / m_{M g m a x} \quad$ (equation 2$)$

\section{Reactor Modeling}

Enhancing the design of the Sol@rmet reactor is a key step to improve the reduction of magnesia. This can be achieved through the investigation of the circulation of the carrier gas and the determination of the gas inlets in a way to purge the emitted $\mathrm{CO}$ gas that improves the reduction. Therefore, simulations are executed taking into account multiple phenomena (fluid mechanics, low pressure, radiative heat transfer, chemical reactions, and phase change) to optimize various operating parameters as the reactor pressure, the argon flow rate, the position and the inlets of the carrier gas.

\section{3.a Settings and Parameters}

The configuration of the solid parts of the Sol@rmet reactor is drawn using CATIA software and imported into the ANSYS software (Figure 3.a). The model geometry to study is built using "Design Modeler" in ANSYS-CFX. It consists of a fluid volume limited by the internal walls of the reactor and a solid volume including the carbon support and the $\mathrm{C} / \mathrm{MgO}$ pellet. A tetrahedral meshing with a mesh size of $2 \mathrm{~mm}$ for the fluid volume and $0.5 \mathrm{~mm}$ for 
the solid volume, as illustrated in Figure 3.b and 3.c, is applied with inflation layers on the critical borders $(0.05 \mathrm{~mm}$ for the pellet as example $)$ and a sphere of influence $(1.8 \mathrm{~mm})$ on the fluid zone surrounding the solid volume. A total number of around 2.7 million elements is obtained that fulfills the criterions with an average skewness, element quality and aspect ratio of $0.22,0.81$ and 2 respectively.
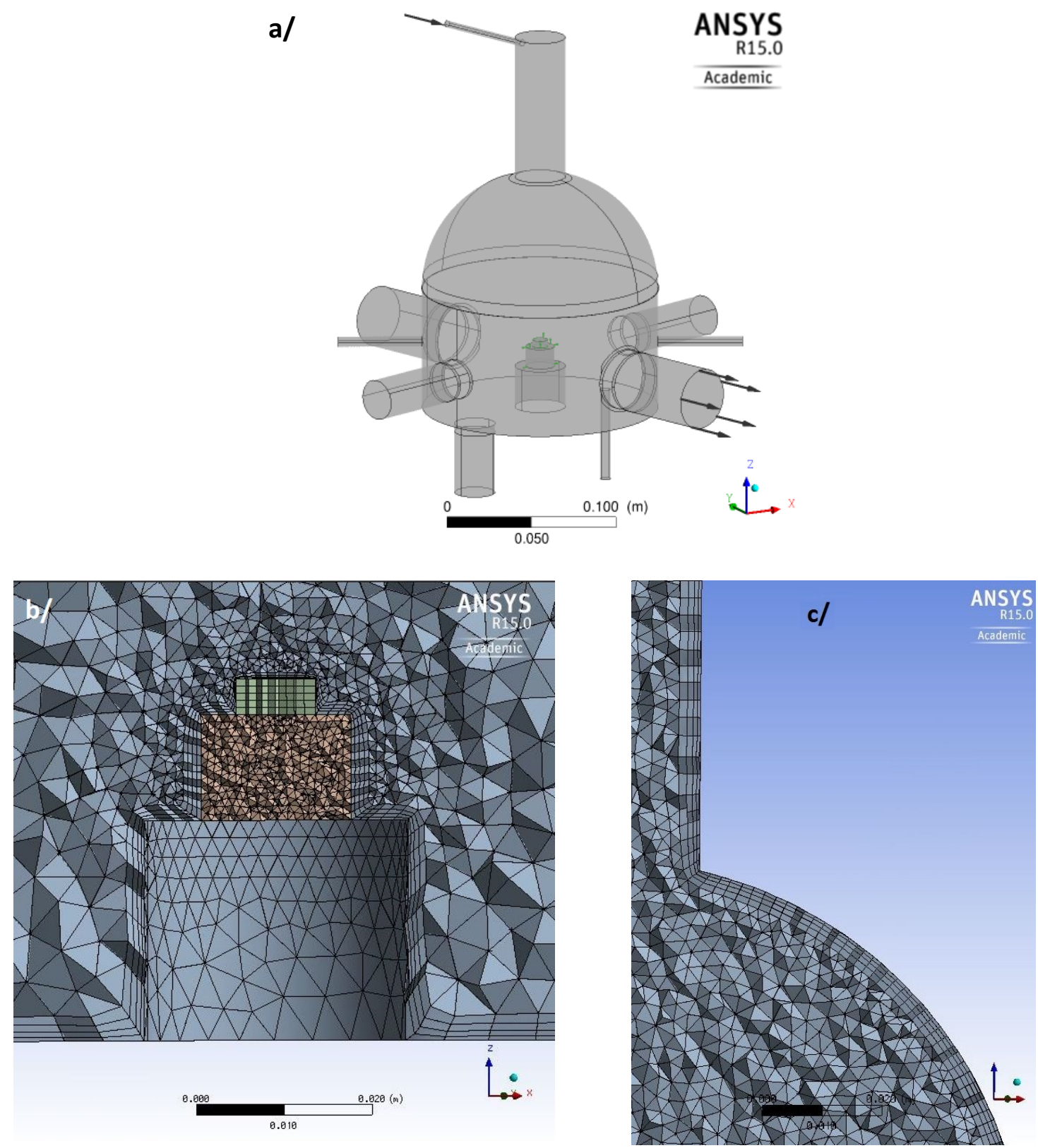

Figure 3.a) Sol@rmet reactor configuration imported from CATIA software and built using "Design Modeler" in ANSYS-CFX, b) Meshing of the C/MgO pellet and its surrounding, c) Meshing of the glass dome. 
The properties of gaseous products (argon, CO) were taken from the "Gas Phase Combustion" library in ANSYS, where the heat capacities are presented as NASA polynomial coefficients. For solid reactants $(\mathrm{C} / \mathrm{MgO}$ molar ratio $=2)$, the heat capacity of the pellet is averaged based on the weight percentage $(62.5 \% \mathrm{MgO}$ and $37.5 \% \mathrm{C})$ while the thermal conductivity is averaged based on the volume percentage ( $48 \% \mathrm{MgO}$ and $52 \% \mathrm{C}$ ). Thus, the assumed pellet properties are a molar mass of $1 \mathrm{~g} \cdot \mathrm{mol}^{-1}$, a volumetric mass density of $2493 \mathrm{~kg} \cdot \mathrm{m}^{-3}$, a heat capacity of $841 \mathrm{~J} \cdot \mathrm{kg}^{-1} \cdot \mathrm{K}^{-1}$ and a thermal conductivity of $95 \mathrm{~W} \cdot \mathrm{m}^{-1} \cdot \mathrm{K}^{-1}$.

During the first simulations, argon is injected at $5 \mathrm{~L} \cdot \mathrm{min}^{-1}$ from the upper part of the glass dome, under the $\mathrm{CaF}_{2}$ window (as a boundary condition for the entry tube). Under this flow and the reactor pressure set at $1000 \mathrm{~Pa}$ as experimentally (as a boundary condition for the exit tube), the fluid is considered incompressible (Mach $<0.04$ ) and the flow laminar with a Reynolds number of 18 in the entry tube and 2 in the exit tube. The "High Resolution" model is used to solve the Navier-Stokes equations and a residual of $10^{-6}$ is used as a convergence criterion for the flow or $10^{-4}$ for the heat transfer and mass fraction. The "Thermal energy" model is used for the heat transfer calculation and the "Steady state" model is used for the flow analysis. The Monte-Carlo model is used, as argon is transparent with a negligible optical depth (Inc Ansys., 2013), to implement the radiations emitted from the internal walls of the glass dome and directed through vectors towards the pellet. The dome surface is decomposed into 16 parts with each has a director vector determined from the "Design Modeler" (see Figure 4 and Table 1). This model is applied to correlate the solar heating on the pellet surface supposing a $1.5 \mathrm{~kW}$ solar furnace and a direct normal irradiation (DNI) of $1000 \mathrm{~W} \cdot \mathrm{m}^{-2}$, meaning a maximal heat power of 15000 suns on the pellet surface. This power is emitted by all the internal surfaces of the dome, thus the surface radiative power to impose on the surface dome is $36200 \mathrm{~W} \cdot \mathrm{m}^{-2}$. Solid-solid reactions cannot be simulated using ANSYS-CFX, so only gaseous emissions ( $\mathrm{Mg}$ and $\mathrm{CO}$ ) from the pellet surface are studied 
using the "multi-components" model. We used the properties of CO (from the ANSYS library) for all the emitted gas as those of $\mathrm{Mg}$ are unknown, this approximation is valid as the molar masses of $\mathrm{CO}$ and $\mathrm{Mg}$ are close. Hence, the fraction of $\mathrm{Mg}$ produced is replaced by $\mathrm{CO}$ taking into account that $\mathrm{CO}$ consists of $54 \%$ of the emitted gases (one mole of $\mathrm{CO}$ produced for each mole of $\mathrm{Mg}$ ). From the experimental measure of the $\mathrm{CO}$ produced over the reaction time, an average production of around $2.3 \times 10^{-8} \mathrm{~kg} \cdot \mathrm{s}^{-1}$ is assessed. Thus, the total production is estimated to $4.26 \times 10^{-8} \mathrm{~kg} \cdot \mathrm{s}^{-1}$ and the surface mass flow of the emitted gases all over the pellet surface is $6.7 \times 10^{-4} \mathrm{~kg} \cdot \mathrm{s}^{-1} \cdot \mathrm{m}^{-2}$.
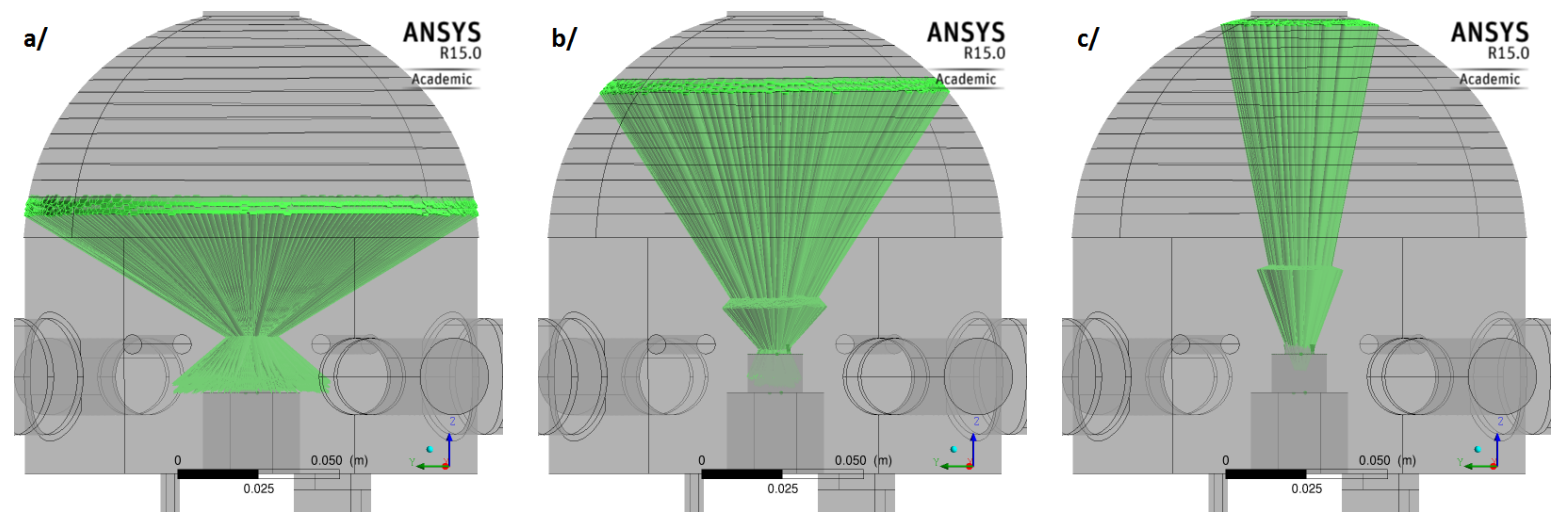

Figure 4. Division of the dome to 16 parts and radiations emitted towards the pellet following different director vectors for three surfaces of the dome.

Table 1. Radiation parameters of the various parts of the Sol@rmet reactor.

\begin{tabular}{ccccc}
\hline & $\begin{array}{c}\text { Carbon } \\
\text { support }\end{array}$ & $\begin{array}{c}\mathrm{C} / \mathrm{MgO} \\
\text { pellet }\end{array}$ & $\begin{array}{c}\text { Glass dome and } \\
\text { fluorine window }\end{array}$ & $\begin{array}{c}\text { Inox 304L (reactor walls) } \\
\text { (Touloukian and Dewitt, 1970) }\end{array}$ \\
\hline Emissivity & 0.9 & 0.9 & 0.8 & 0.2 \\
$\begin{array}{c}\text { Fraction of } \\
\text { scattered light }\end{array}$ & 1 & 1 & 1 & 0.3 \\
\hline
\end{tabular}

\section{3.b Simulations of the first configuration}

Simulations of the first configuration with one argon entry proved that the gas flow in the reactor is affected by the radiation model, but not influenced by the emissions of gases. 
Figure 5 shows that the circulation of the flow inside of the reactor mainly consists of three parts where some of the argon crosses through the reactor smoothly to the exit tube, another part creates a vortex in the lower part of the reactor surrounding the pellet, and the third part develops swirls under the dome due to the higher temperatures of the dome walls (see Figure 5.c). The entry velocity is averaged to $6.63 \mathrm{~m} \cdot \mathrm{s}^{-1}$ with a maximum in the center of the tube of around $12.3 \mathrm{~m} \cdot \mathrm{s}^{-1}$, and this value drops to velocities not exceeding $0.2 \mathrm{~m} \cdot \mathrm{s}^{-1}$ under the dome. In the exit tube, the flow is eccentric upwards (Figure 5.b) with an average velocity of 0.08 $\mathrm{m} \cdot \mathrm{s}^{-1}$ and a maximal velocity of $0.21 \mathrm{~m} \cdot \mathrm{s}^{-1}$ in the center. 


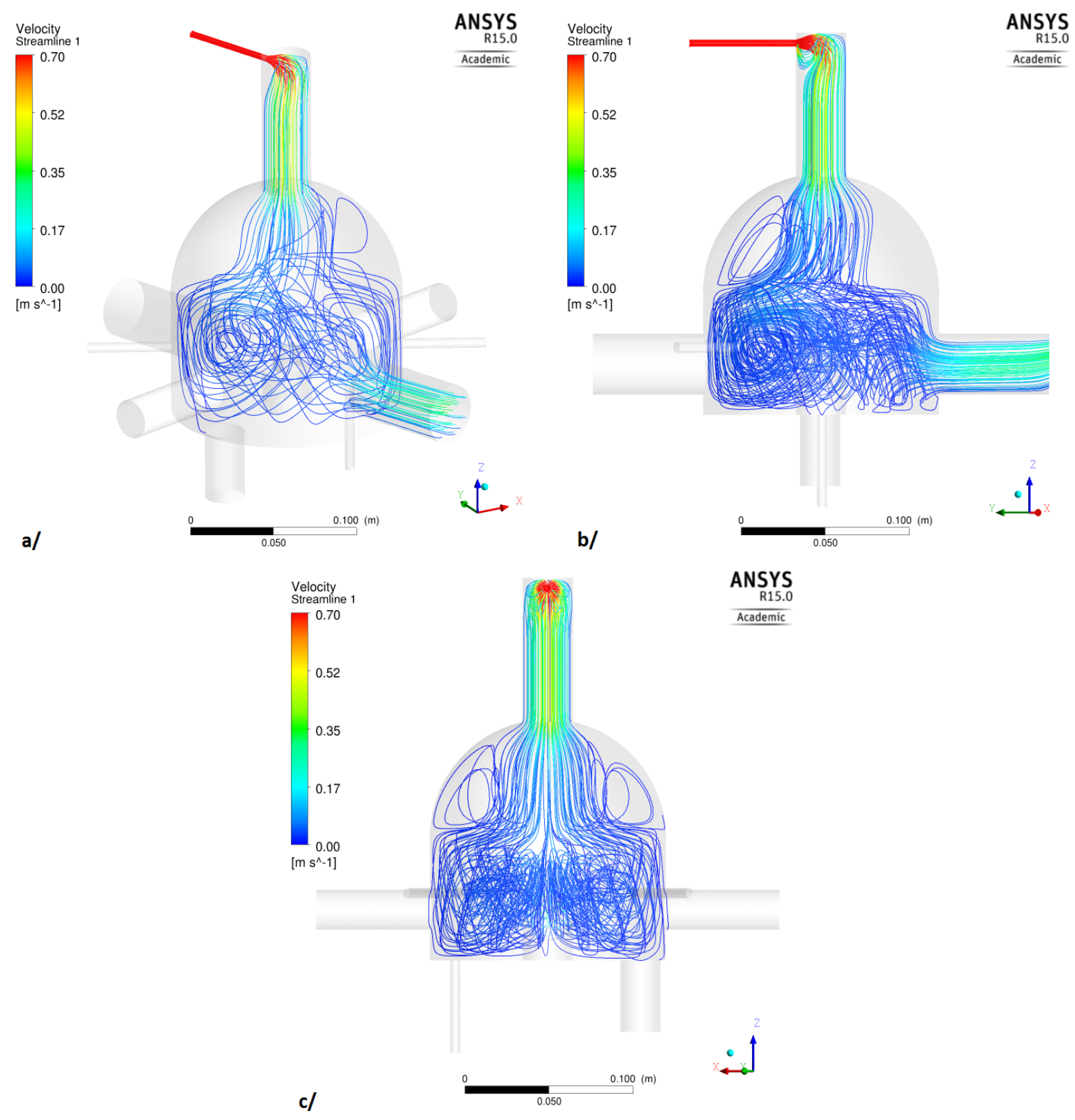

Figure 5. Argon flow in the reactor from the a) 3/4 view, b) side view and c) back view.

The temperature of the glass dome is around $750 \mathrm{~K}$, while that of the lower part of the metallic reactor is $650 \mathrm{~K}$ (see Figure 6.a). The variation of the temperature between the walls and the center of the reactor is one of the parameters responsible for the vortex circulation of the argon flow. Figures 6.b and 6.c confirm the conformity of the simulation results with experiments as the pellet temperature is not uniform all over the surface. In fact, the temperature reaches around $2100 \mathrm{~K}$ at the center of the pellet, while this value drops to around $1600 \mathrm{~K}$ on the extremities of the pellet. 


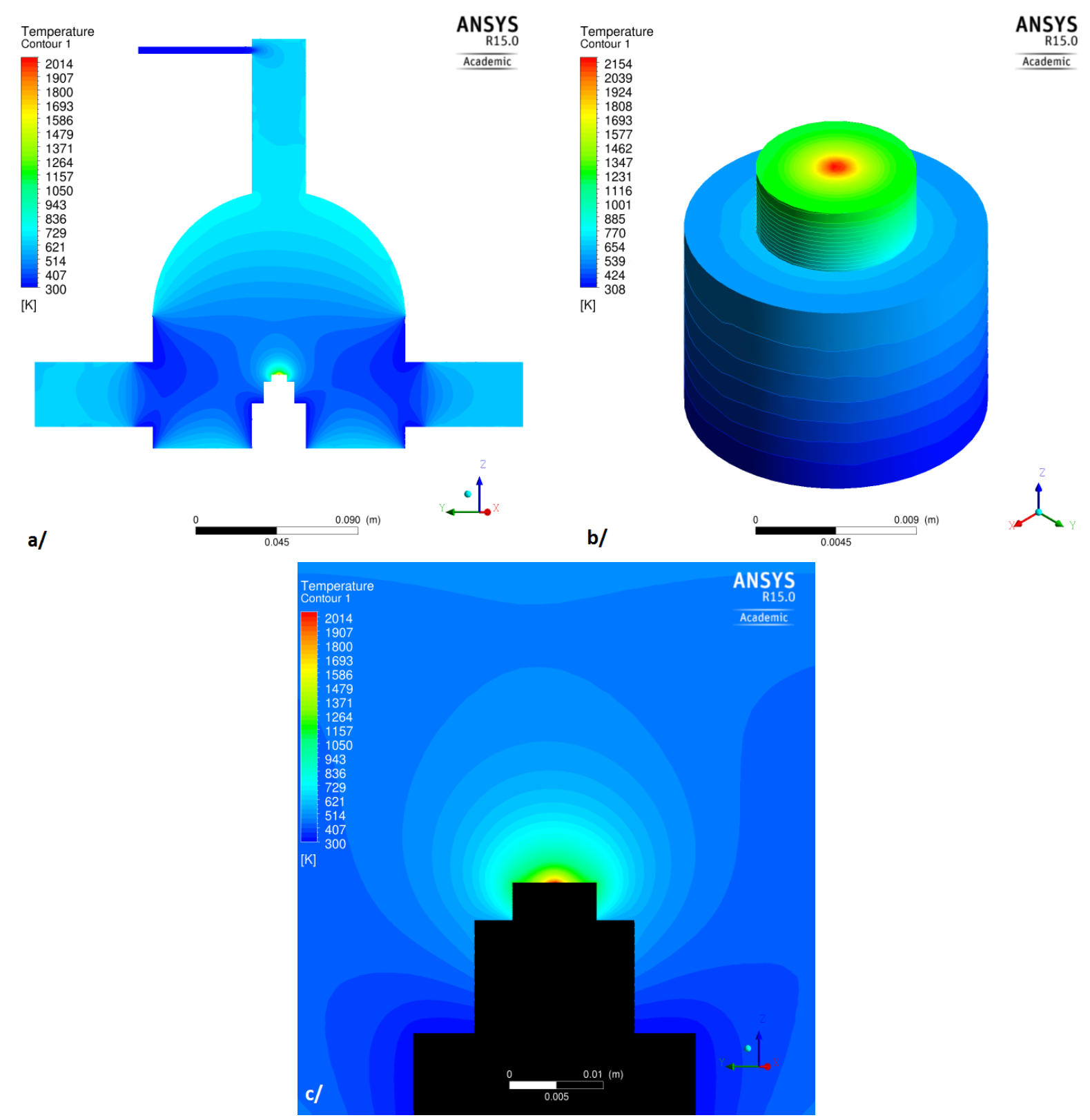

Figure 6. Temperature profile a) of the reactor walls, b) of the pellet surface and c) around the pellet.

The gaseous emissions from the pellet surface are considered negligible as the mass fraction of $\mathrm{CO}$ is less than 0.07 , thus they are diluted in the argon flow. As the circulation of argon creates swirls near the metallic parts and the dome of the reactor, some of the diluted products $(\mathrm{Mg})$ are condensed on those walls, which confirms the experimental observation. Figure 7 demonstrates that the profile of the gaseous emissions is circular which is explained 
by the symmetrical flow of argon shown in Figure 5.c. However, it is clear that the circular profile is dragged towards the vortex in the opposite way of the exit tube (see Figure 5.b).

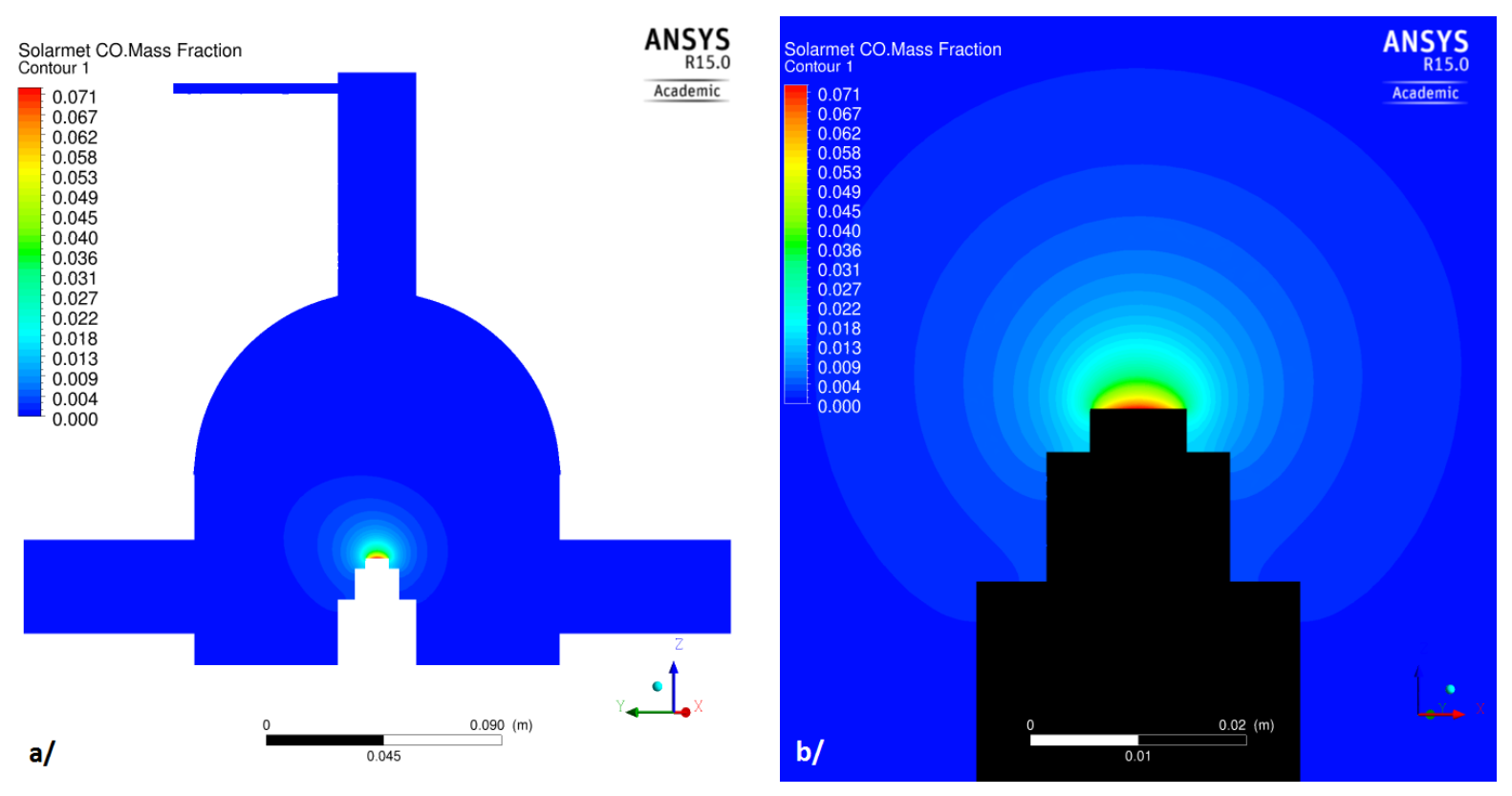

Figure 7. Mass fraction of gaseous emissions from the pellet surface: a) an overview of the reactor,

b) a close-up around the pellet.

\section{3.c Improvement of the reactor design}

In this section, we studied the effect of some parameters and design modification on the circulation of argon in the Sol@rmet reactor. First, we investigated the consequences of increasing the reactor pressure to $10^{4} \mathrm{~Pa}$ which rises the Reynolds number to 187 (still considered a laminar flow) at the same argon flow and entry velocity as the argon kinematic viscosity decreases. This will create higher velocities under the dome reaching $0.6 \mathrm{~m} \cdot \mathrm{s}^{-1}$ with more circulations (spirals and swirls) directed towards the backward side of the reactor, thus repressing the flow from exiting the reactor. The products $(\mathrm{CO}$ and $\mathrm{Mg})$ are more rapidly evacuated from the pellet surface towards the backward of the reactor which is advantageous. However, the products are not directly aspirated to the exit due to the excessive circulation, thus more magnesium will be condensed inside the reactor (metallic parts and dome) and not 
on the filter. When decreasing the reactor pressure to $500 \mathrm{~Pa}$, similar results as those of 1000 $\mathrm{Pa}$ are obtained. At lower pressures $(100 \mathrm{~Pa})$, the simulation converged nevertheless the software cracked and did not take into consideration the effect of the radiation heating.

The second parameter to be evaluated is the argon flow in the entry. Experimentally, for an argon flow lower than $3 \mathrm{~L} \cdot \mathrm{min}^{-1}$, oxygen is still present in the reactor which is noxious for the reduction. For higher flow $\left(20 \mathrm{~L} \cdot \mathrm{min}^{-1}\right)$, an average entry velocity of $28 \mathrm{~m} \cdot \mathrm{s}^{-1}$ is achieved with a Reynolds number of 77 (at $1000 \mathrm{~Pa}$ ) meaning that the flow is always considered laminar. For this flow, similar circulations are obtained as those at $5 \mathrm{~L} \cdot \mathrm{min}^{-1}$ under $10^{4} \mathrm{~Pa}$, hence this will not optimize the design as more products will condense inside the reactor.

A minor amelioration of the reactor design is gained when rotating the argon entry of $90^{\circ}$ (perpendicular to the exit) as the produced $\mathrm{CO}$ is more driven with the flow directly towards the exit tube, contrarily to the previous configuration where it was driven towards the backward part of the reactor. When rotating the argon entry of $180^{\circ}$ (entry and exit tubes are parallel in the same side), a large part of the flow circulates under the $\mathrm{C} / \mathrm{MgO}$ pellet to the exit tube while the small swirls in the center above the pellet are not sufficient to drive out the products from around the pellet surface. Despite that, this configuration inhibits the deposition of the produced magnesium inside the reactor (metallic parts and dome).

During the following simulations, the first configuration (Figure 5) and parameters are taken again and an additional entry for argon is added from the bottom of the metallic part of the reactor. The calculated velocity from the upper entry is $4 \mathrm{~m} \cdot \mathrm{s}^{-1}$ corresponding to $3 \mathrm{~L} \cdot \mathrm{min}^{-1}$ flow, while that from the bottom entry is $6.63 \mathrm{~m} \cdot \mathrm{s}^{-1}\left(7 \mathrm{~L} \cdot \mathrm{min}^{-1}\right.$ argon flow). Figure 8.a shows that the argon inserted from the upper entry passes smoothly around the pellet to the exit tube. From the other side, the argon inserted from the bottom entry develops two large symmetric swirls, circulating between the dome and the bottom metallic part of the reactor, that are rapidly sucked through the exit tube (Figure 8.b and 8.c). This double circulation 
creates a high-velocity flow in the exit tube reaching values up to $0.7 \mathrm{~m} \cdot \mathrm{s}^{-1}$ as observed in Figure 8.d, compared to $0.21 \mathrm{~m} \cdot \mathrm{s}^{-1}$ using one gas entry. The temperature and emissions profiles are similar to the case of one argon entry with an additional advantage that the $\mathrm{CO}$ circular profile is more driven by the argon from the bottom entry. Therefore, the double argon entry allows to efficiently purge the emitted products towards the exit tube while prohibiting their deposition on the reactor walls, thus improving the reduction rate and consequently both the $\mathrm{Mg}$ yield and purity on the filter.

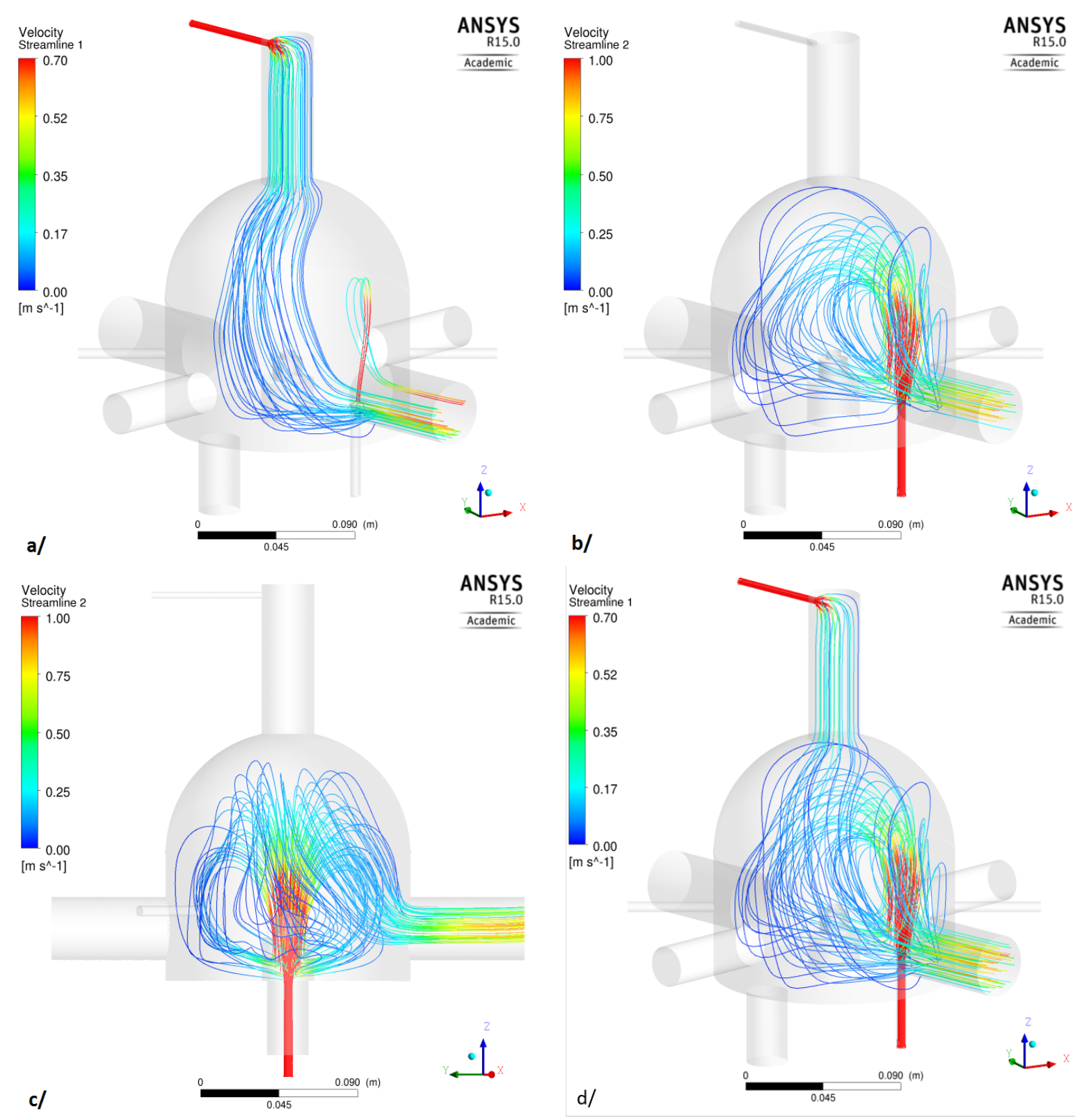

Figure 8. Circulation lines of the argon flow from a) the upper entry (3/4 view), b) the bottom entry (3/4 view), $c$ ) the bottom entry (back view), and d) both the upper and the bottom entries (3/4 view). 


\section{Solar Experiments}

In the following section, we present the results of the magnesia carbothermal reduction experiments performed under low pressures in the Sol@rmet reactor using concentrated solar energy as a heating source. Importantly, we investigate the effect of various parameters as the gas circulation in the reactor, the milling of the $\mathrm{C} / \mathrm{MgO}$ powders and the catalytic effect of binders (PVA, starch and starch-bentonite) and metal catalysts (Fe and Ni) to improve the magnesia reduction rate and thus the magnesium production.

\subsection{Experimental validation of the simulation results}

Magnesia carbothermal reduction experiments are performed using birch charcoal to investigate the effect of the argon circulation and to confirm the simulation results. For the following experiments, $\mathrm{C} / \mathrm{MgO}$ particles are milled together manually. $\mathrm{C} / \mathrm{MgO}$ pellets with $10 \%$ PVA binder (pellet weight of about $140 \mathrm{mg}$ ) are reduced under 900-1000 $\mathrm{Pa}$ and the temperature is increased progressively, by gradually opening the shutter, over $15 \mathrm{~min}$ and held until the CO production becomes lower than $200 \mathrm{ppm}$. In the first experiment, argon is injected from the upper entry at $3.5 \mathrm{~L} \cdot \mathrm{min}^{-1}$. The reaction begins at $1920 \mathrm{~K}$, reaches up to $2230 \mathrm{~K}$ (after $15 \mathrm{~min}$ ) and is held at this temperature for 9 min until the reaction ends. Under those conditions, a $\mathrm{Mg}$ yield of $52 \%$ is obtained with a product purity of $87 \%$. During the second experiment, argon is injected at $0.5 \mathrm{~L} \cdot \mathrm{min}^{-1}$ from the upper entry and at $3 \mathrm{~L} \cdot \mathrm{min}^{-1}$ from the bottom entry. The reaction begins at $1970 \mathrm{~K}$ and ends at $2130 \mathrm{~K}$ after $17 \mathrm{~min}$ (progressively for $15 \mathrm{~min}$ and held for $2 \mathrm{~min}$ ) giving a $\mathrm{Mg}$ yield of $68 \%$ with $87 \%$ powders purity. In a third experiment, using the same double argon flow, a $\mathrm{Mg}$ yield of $69 \%$ with $95 \%$ purity is obtained for a $\mathrm{C} / \mathrm{MgO}$ pellet of $400 \mathrm{mg}$ affirming the second experimental result. These experiments confirmed the simulation results about the effect of the argon circulation inside the reactor proving that purging the products from the pellet surface improves the 
reduction rate. Therefore, a double argon entry is admitted for the experiments during the following sections.

\subsection{Effect of the mechanical milling of the $\mathrm{C} / \mathrm{MgO}$ powders}

During this experiment, carbon and magnesia powders are mechanically milled with the $10 \%$ PVA binder using Pulverisette 4 mill then dry pressed at one ton (250 mg pellet). This procedure allows obtaining a mechanically stable pellet more convenient for a continuous production process. Moreover, it has been proved that milling allows decreasing the particle size thus enhancing the $\mathrm{C} / \mathrm{MgO}$ surface area and improving the reduction (Nusheh et al., 2010). Figure 9 proves that the mechanical milling of the $\mathrm{C} / \mathrm{MgO}$ powders improves the integrity of the pellet and prevents the existence of magnesia agglomerates thus increasing the $\mathrm{C} / \mathrm{MgO}$ contact. Granulometry measurements confirmed that magnesia powders have a $\mathrm{D}_{90}$ particle size of $13 \mu \mathrm{m}$ when sonicated, however they are agglomerated into large particles due to humidity. Further, the $\mathrm{D}_{90}$ particle size of $\mathrm{C} / \mathrm{MgO}$ powders (without sonification) decreases from 157 to $117 \mu \mathrm{m}$ when mechanically milled. Moreover, SEM images reveal that $\mathrm{C} / \mathrm{MgO}$ contact is higher when powders are milled as the carbon particle shown in Figure 9.f has almost no contact with $\mathrm{MgO}$ particles on the contrary to that shown in Figure 9.e. Argon is injected from the upper entry at $1 \mathrm{~L} \cdot \mathrm{min}^{-1}$ and from the bottom entry at $3.5 \mathrm{~L} \cdot \mathrm{min}^{-1}$ to approach the simulation findings. Under those flows and after improving the reactor sealing, the primary vacuum allows to reach operating pressures of 830-840 $\mathrm{Pa}$. Temperature is raised progressively over the reaction time $(22 \mathrm{~min})$ from $940 \mathrm{~K}$ at $10 \%$ opening of the shutter reaching up to $2570 \mathrm{~K}$ at full opening. At the end of the reaction, the major part of the produced magnesium is collected from the metallic filter in the exit tube $(83 \mathrm{mg})$ while only $10 \mathrm{mg}$ are deposited on the reactor metallic walls. The glass dome remains clean and does not impede the pellet heating through the solar radiations which is beneficial for a continuous production process. The collected powders are analyzed and quantified by XRD to determine 
the purity of the powder. The XRD pattern of the powders collected from the filter is presented in Figure 10 and reveals that only $\mathrm{Mg}$ and $\mathrm{MgO}$ peaks are detected. Hence, under the previous conditions and by milling the $\mathrm{C} / \mathrm{MgO}$ powders, a $\mathrm{Mg}$ yield of $84.7 \%$ is achieved with a product purity of $93 \%$ for those collected from the filter and $83 \%$ for those deposited on the reactor walls. This $\mathrm{Mg}$ yield is higher by around $15 \%$ than that obtained in section 4.1 where no mechanical milling of $\mathrm{C} / \mathrm{MgO}$ powders was performed.
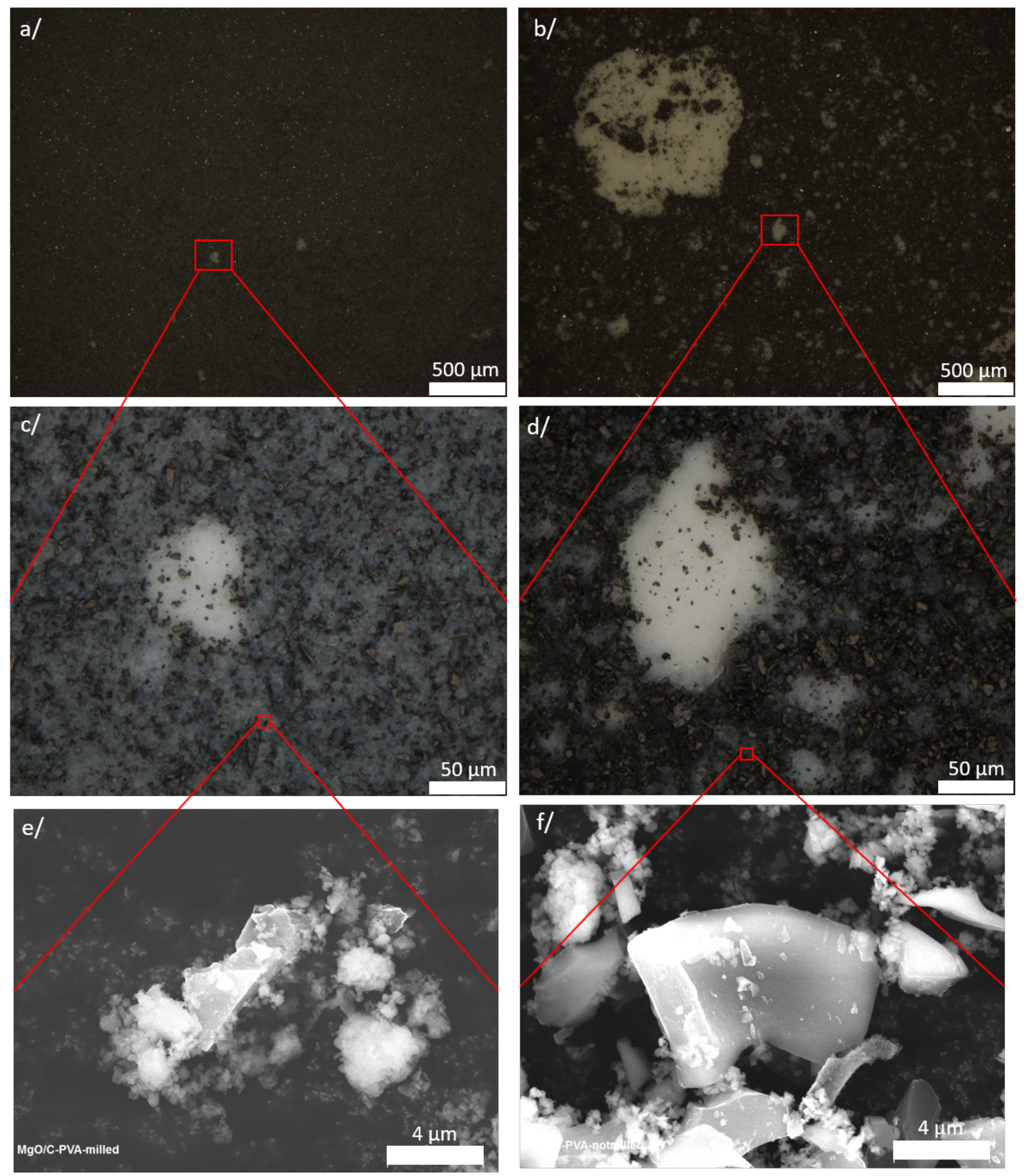

Figure 9. Optical and SEM images of a), c) and e) $\mathrm{C} / \mathrm{MgO}+10 \%$ PVA milled powders, b), d) and f) non-milled powders. 


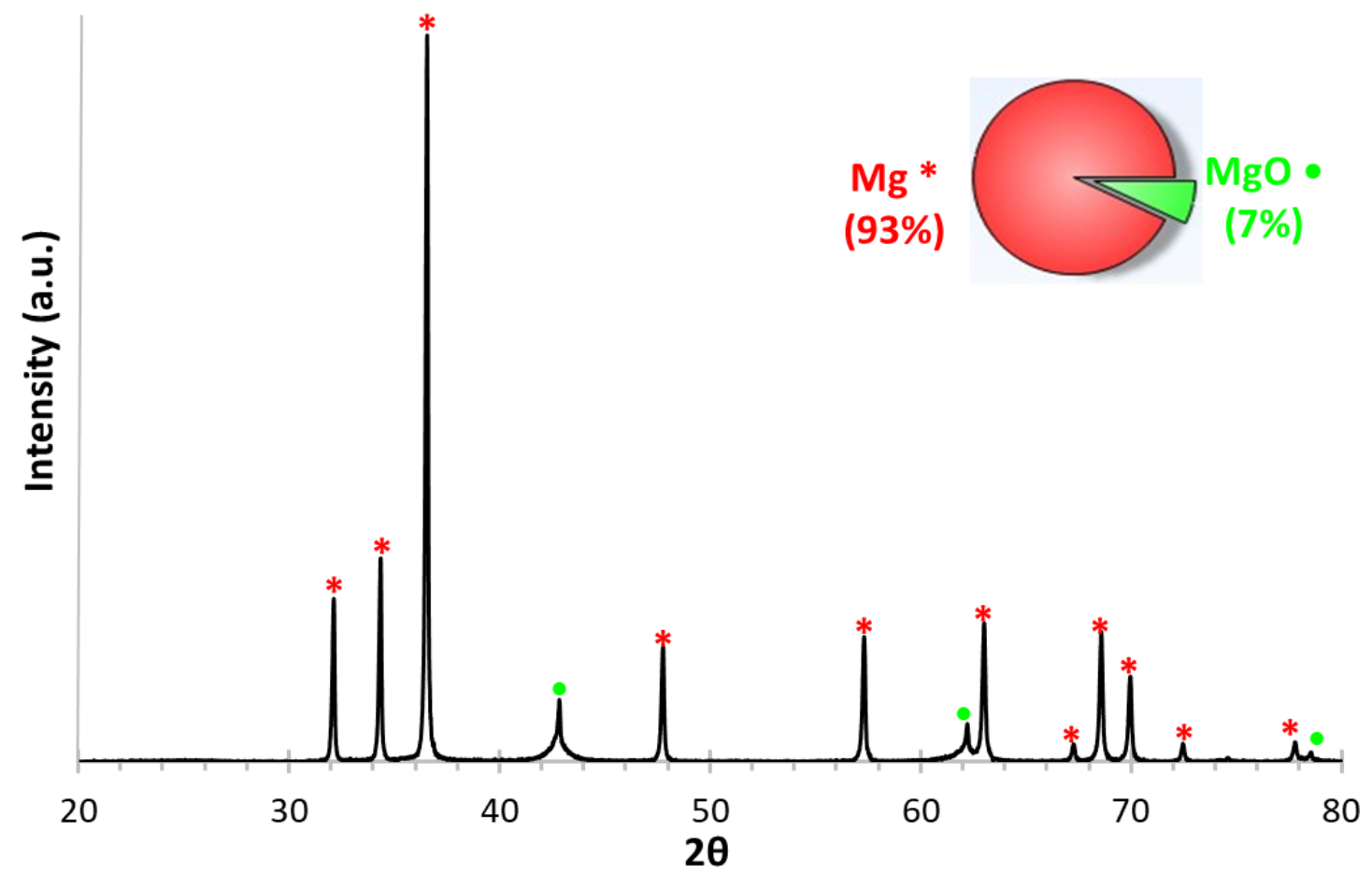

Figure 10. XRD pattern of the powders collected from the filter after the carbothermal reduction, under low pressures, of the milled $\mathrm{C} / \mathrm{MgO}+10 \%$ PVA pellet.

\subsection{Effect of charcoal type}

Being one of the most important parameters during the carbothermal reduction of magnesia, we investigated the effect of using two charcoals, chimney charcoal obtained from the house chimney through the combustion of woods and birch charcoal obtained by pyrolysis of birch wood at $770 \mathrm{~K}$ for four hours. Previously, several researchers studied the effect of the carbon type proving that amorphous charcoal is more attractive than graphite (Fruehan and Martonik, 1976). In fact, when the boundary phase reaction dominates, as in our case for experiments under low pressures, the carbon type affects the reaction rate with a preference for charcoal over graphite (Rongti et al., 2002). Recently, Puig et al. proved that birch charcoal gives a better yield than carbon black (Puig and Balat-Pichelin, 2018). However, one should consider the properties of the charcoal. Herein, experiments are 
performed by heating the $\mathrm{C} / \mathrm{MgO}$ pellets gradually up to $60 \%$ shutter opening over $18 \mathrm{~min}$ to compare the performance of chimney charcoal to that of birch charcoal.

Figure 11 shows the variation of the temperature and gaseous emissions $\left(\mathrm{CO}\right.$ and $\left.\mathrm{CO}_{2}\right)$ measured by the pyrometer and the gas analyzer respectively during the gradual heating over the reaction period. As observed, the $\mathrm{CO}$ production is up to three times higher using birch charcoal compared to when chimney charcoal is used, with the temperature reaching $2250 \mathrm{~K}$ (at $60 \%$ shutter) compared to $1700 \mathrm{~K}$ for the chimney charcoal. $\mathrm{CO}_{2}$ is produced at the beginning of the reaction then becomes negligible. An important point to consider is that more $\mathrm{CO}_{2}$ is emitted when using chimney charcoal, which is consistent with the previous findings stating that a lower $\mathrm{CO}_{2}$ production at the beginning of the reaction is more beneficial for the reduction (Puig and Balat-Pichelin, 2018). The Mg yield reached using birch charcoal is $63 \%(95 \% \mathrm{Mg}$ purity) compared to $21 \%$ (97\% Mg purity) using chimney charcoal. This is mainly attributed to a major parameter, the fixed carbon content, that must be considered when using charcoals during magnesia reduction. Previous researches have proved that a minimum fixed carbon content of $85 \%$ is required to meet the metallurgical industry needs (Griessacher et al., 2012). In our case, thermogravimetry analysis is executed displaying that the fixed carbon content of chimney charcoal is $42.6 \%$ which is very low compared to that of birch charcoal (around 93\%). This was observed visually by the white color of the remaining of the pellet after the reaction, representing magnesia, meaning that the carbon quantity is not sufficient for the reduction. Accordingly, the charcoal should have good properties including a high fixed $\mathrm{C}$ content, surface area and porosity to be suitable for the magnesia reduction. Hence, a detailed study probing the effect of the biomass pyrolysis conditions (biomass source, heating rate, temperature, use of leavening agents) on the biochar properties and their reduction capacity will be published apart. 


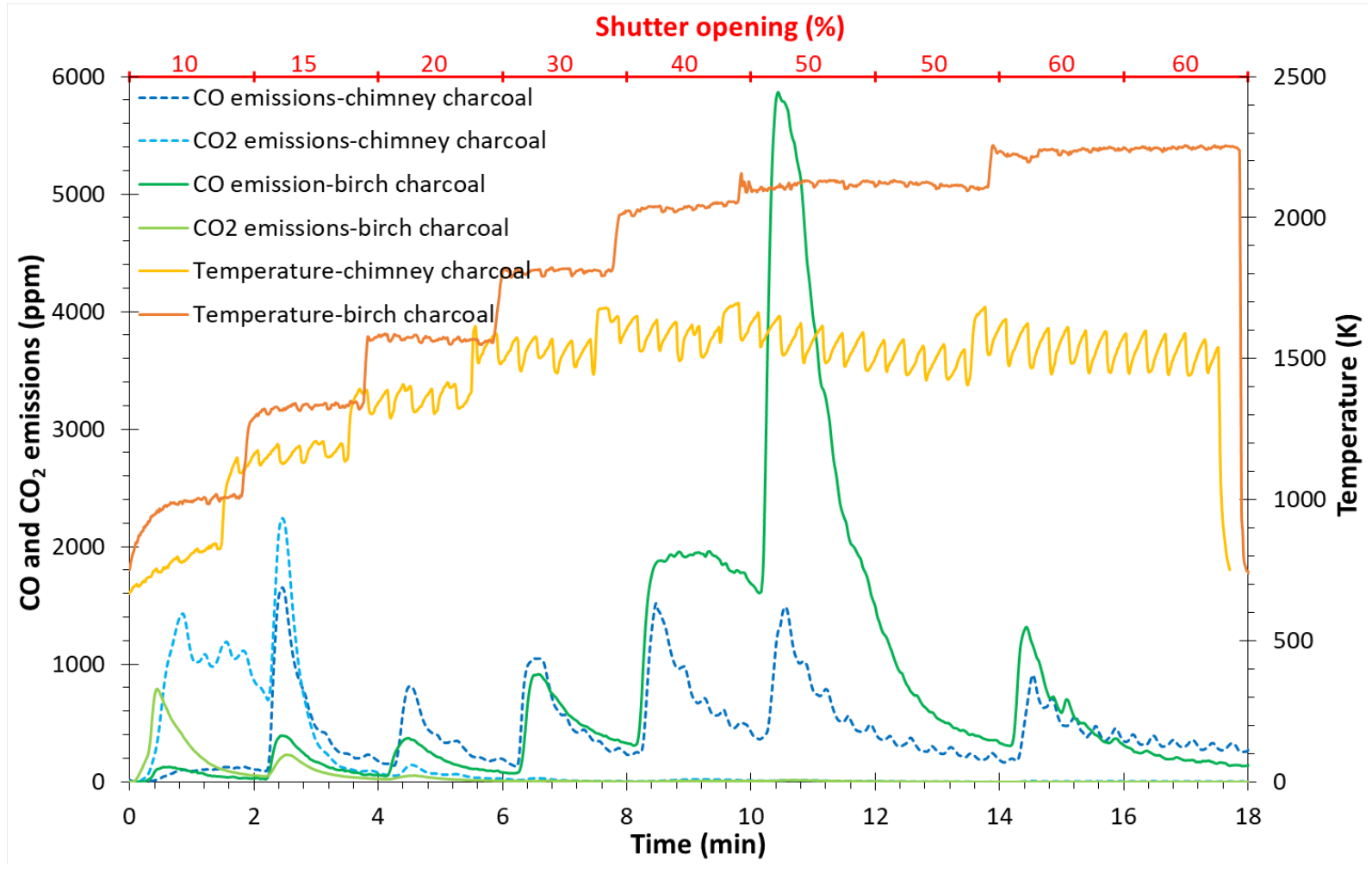

Figure 11. Temperature and gaseous emission (CO and $\left.\mathrm{CO}_{2}\right)$ variation during the magnesia carbothermal reduction using chimney or birch charcoals as reducing agents.

\subsection{Catalytic-like role of binders}

During the carbothermal reduction, the $\mathrm{C} / \mathrm{MgO}$ pellet should be mechanically stable to resist the sudden rise of the temperature and prevents its explosion. Additionally, for the prospective semi-continuous magnesium production process, pellets must bear the mechanical movement during the feeding in the reactor. Thus, we used several binders (as PVA, starch, and bentonite) to provide those mechanical properties during the pelletization by dry pressing. The catalytic-like effect of the PVA binder is first proved during the experiment using only one argon entry (from the upper part of the glass dome) as the produced magnesium yield increased from $39 \%$ (60\% purity) without binder to $48 \%$ ( $82 \%$ purity) with $10 \%$ PVA. This result accords with the conclusions on the catalytic role of the calcium fluoride binder (Tian et al., 2012). Thus, motivated by the previous findings demonstrating the good mechanical strength of pellets with 5\% starch-5\% bentonite 
(Chubukov et al., 2018), it becomes more necessary to investigate the catalytic-like effect of these binders. Experiments are performed by opening the shutter of $10 \%$ every two minutes until it is fully open, which allows a gradual increase of the temperature over the reaction time. Table 2 compares the results of the reduction using PVA, starch or starch-bentonite binders based on the total $\mathrm{Mg}$ yield, the collected powders purity (determined through semiquantitative $\mathrm{XRD}$ ), as well the maximum temperature reached and $\mathrm{CO}$ peak. During experiments A2, A3 and A4 using 5 or $10 \%$ starch binders, high temperatures up to $2600 \mathrm{~K}$ are attained with a total $\mathrm{Mg}$ yield of around $76 \%$ with $93 \% \mathrm{Mg}$ purity for the powders collected on the filter and $74 \% \mathrm{Mg}$ purity for those collected on the reactor walls. However, the quantity of the powders collected on the reactor walls is not important compared to that collected on the filter ( $9 \mathrm{mg}$ compared to around $75 \mathrm{mg}$ in experiment $\mathrm{A} 2$ for example). The magnesia reduction during experiment $\mathrm{A} 5$ is a little less good with a total $\mathrm{Mg}$ yield of $68 \%$ due to the high winds (up to $16 \mathrm{mph}$ ) that can move slightly the focal point of the parabola, thus decreases the radiations on the pellet surface. The catalytic-like effect of PVA binder is again highlighted as higher $\mathrm{Mg}$ yield (of about $85 \%$ ) is obtained compared to when using a starch binder. Regarding the use of 5\% starch-5\% bentonite, experiments A6-A10 proved that it has a catalytic role exceeding that of PVA binder with Mg yields higher than $87 \%$ reached, except during experiment A9 where the DNI decreased from 912 to $880 \mathrm{~W} \cdot \mathrm{m}^{-2}$ during the reaction. Thus, it is recommended for a superior magnesia reduction performance to operate under good weather conditions with a DNI not lower than $950 \mathrm{~W} \cdot \mathrm{m}^{-2}$. The highest CO peak of around $7000 \mathrm{ppm}$ is observed during experiment $\mathrm{A} 10$, while the highest $\mathrm{Mg}$ yield of around $96 \%$ (with $96 \% \mathrm{Mg}$ purity for powders collected on the filter) is obtained during experiment A7. 
Table 2. Comparison of the magnesia carbothermal reduction using various binders (PVA, starch, and bentonite) in term of Mg yield and purity of the powders collected on the filter and reactor walls.

\begin{tabular}{|c|c|c|c|c|c|c|c|c|c|}
\hline & binder & $\begin{array}{c}\mathrm{m}_{\text {pellet }} \\
(\mathrm{mg})\end{array}$ & $\begin{array}{l}\mathrm{T}_{\max } \\
(\mathrm{K})\end{array}$ & $\begin{array}{l}\mathrm{CO}_{\max } \\
(\mathrm{ppm})\end{array}$ & $\begin{array}{c}\mathrm{m}_{\text {walls }} \\
(\mathrm{mg})\end{array}$ & $\% \mathrm{Mg}_{\text {walls }}$ & $\begin{array}{l}\mathrm{m}_{\text {filter }} \\
(\mathrm{mg})\end{array}$ & $\% \mathrm{Mg}_{\text {filter }}$ & $\begin{array}{l}\text { Total } \mathrm{Mg} \\
\text { yield }(\%)\end{array}$ \\
\hline $\mathrm{A} 1$ & $10 \%$ PVA & 252 & 2574 & 6426 & 10.1 & $83^{*}$ & 82.7 & $93^{*}$ & 84.7 \\
\hline A2 & $10 \%$ starch & 250 & 2550 & 4755 & 9.0 & 74 & 74.7 & 93 & 76.2 \\
\hline A3 & $5 \%$ starch & 253 & 2609 & 5878 & 10.7 & $74^{*}$ & 79.6 & $93 *$ & 77.4 \\
\hline A4 & $5 \%$ starch & 191 & 2554 & 4285 & 12.0 & 74 & 55 & 93 & 74.8 \\
\hline A5 & $5 \%$ starch & 251 & 2459 & 4104 & 11.2 & $59^{*}$ & 67.4 & $96^{*}$ & $\begin{array}{c}68.0 \\
\text { (high wind) }\end{array}$ \\
\hline A6 & $\begin{array}{l}5 \% \text { starch - } \\
5 \% \text { bentonite }\end{array}$ & 248 & 2489 & 6365 & 21.4 & 58 & 77.3 & 96 & 87.4 \\
\hline A7 & $\begin{array}{l}5 \% \text { starch }- \\
5 \% \text { bentonite }\end{array}$ & 248 & 2486 & 6783 & 21.8 & $58 *$ & 85.7 & $96^{*}$ & 95.8 \\
\hline A8 & $\begin{array}{l}5 \% \text { starch - } \\
5 \% \text { bentonite }\end{array}$ & 208 & 2470 & 5036 & 15.4 & 58 & 69.1 & 96 & 90.6 \\
\hline A9 & $\begin{array}{l}5 \% \text { starch - } \\
5 \% \text { bentonite }\end{array}$ & 249 & 2477 & 5368 & 13.1 & 58 & 70 & 96 & $\begin{array}{c}75.2 \\
\text { (low DNI) }\end{array}$ \\
\hline A 10 & $\begin{array}{l}5 \% \text { starch - } \\
5 \% \text { bentonite }\end{array}$ & 249 & 2311 & 7032 & 18.8 & 58 & 80.2 & 96 & 88.3 \\
\hline
\end{tabular}

*Determined through semi-quantitative XRD measurements. For other experiments, these values are admitted.

The catalytic-like behavior of the bentonite binder can be attributed to the better integrity of the $\mathrm{C} / \mathrm{MgO}$ particles during the mechanical milling rather than to a chemical catalysis reaction. This suggestion is confirmed by the optical and scanning electron microscopy as no agglomerates were found using starch-bentonite binder with mechanical milling (Figure 12.e) while some large magnesia agglomerates (around $100 \mu \mathrm{m}$ ) were observed when using starch with mechanical milling (Figure 12.c). The effect of milling is again confirmed as extra-large agglomerates $(>500 \mu \mathrm{m})$ are avoided (Figure 12.a). Granulometry measurements confirmed these observations as the $\mathrm{D}_{90}$ particle size of milled $\mathrm{C} / \mathrm{MgO}$ powders with $10 \%$ starch is $91 \mu \mathrm{m}$ compared to $22 \mu \mathrm{m}$ when $5 \%$ starch - 5\% bentonite is used. SEM images have shown that some $\mathrm{C}$ particles have no contact with $\mathrm{MgO}$ particles when powders with 
$5 \%$ starch $-5 \%$ bentonite are not milled, while the $\mathrm{C} / \mathrm{MgO}$ contact increases when powders are milled with $10 \%$ starch and is more important when powders are milled with $5 \%$ starch $5 \%$ bentonite. Furthermore, the bentonite binder supports a higher temperature than the starch binder (up to $1000 \mathrm{~K}$ ) that prevents the $\mathrm{MgO}$ sintering at the beginning of the reaction.
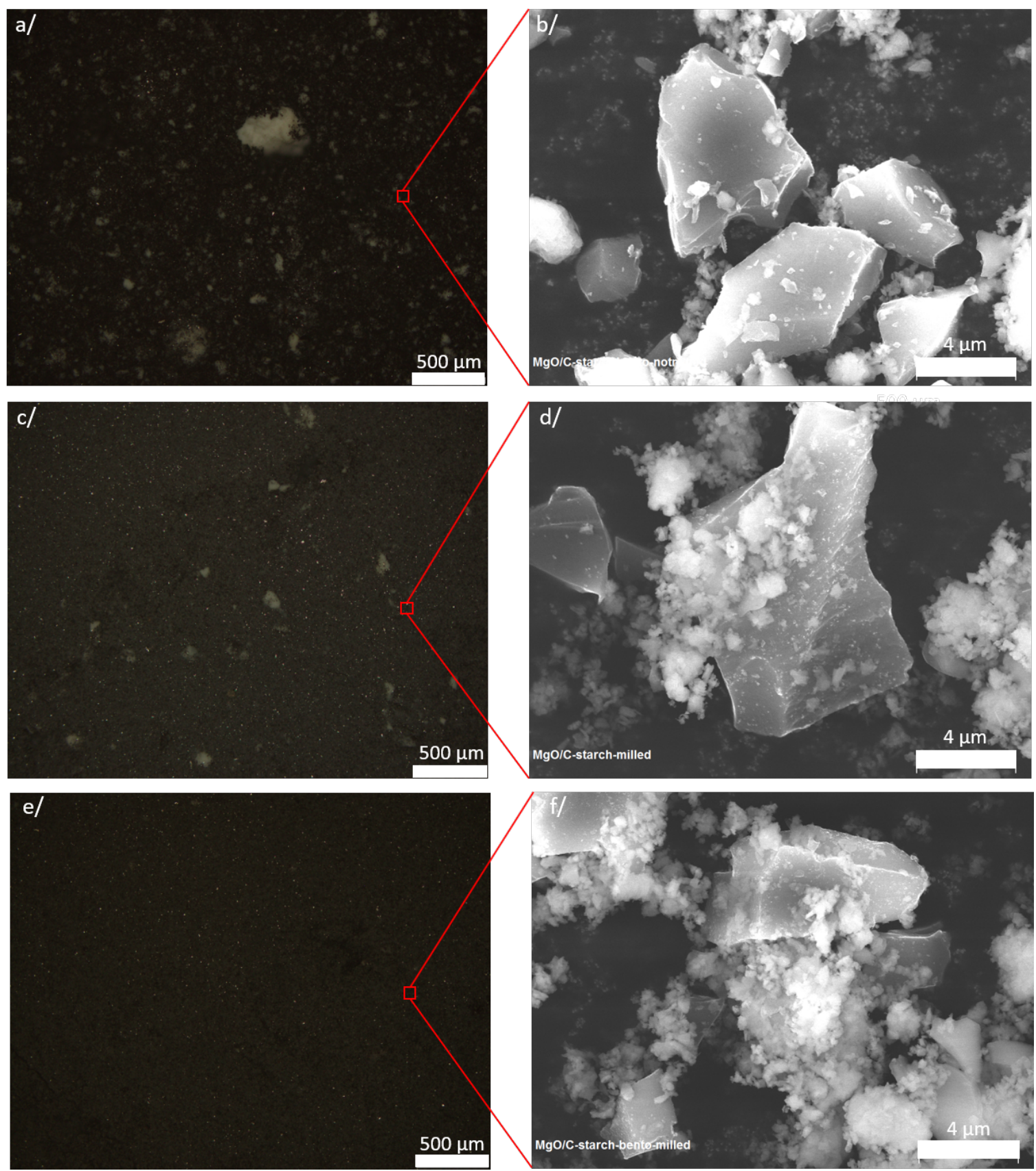

Figure 12. Optical and SEM images of C/MgO powders: a) and b) non-milled with 5\% starch - 5\% bentonite, c) and d) milled with 10\% starch, e) and f) milled with 5\% starch - 5\% bentonite. 
The granulometric analysis of the collected powders from experiments A1, A3, and A7 where PVA, starch and starch-bentonite binders were used, showed that most particles (> $90 \%$ ) are smaller than $100 \mu \mathrm{m}$ with a considerable amount up to $40 \%$ smaller than $10 \mu \mathrm{m}$. These findings are confirmed by scanning electron microscopy (SEM) images, presented in Figure 13 for the powders collected from experiment A3, where agglomerates of submicron particles and submicron magnesium crystals were observed. It is well noticed that the powders collected on the walls (Figure 13.c and 13.d) are somewhat larger than those collected on the filter (Figure 13.a and 13.b) with more magnesium oxide spotted on the surface of the crystals and of the agglomerates.
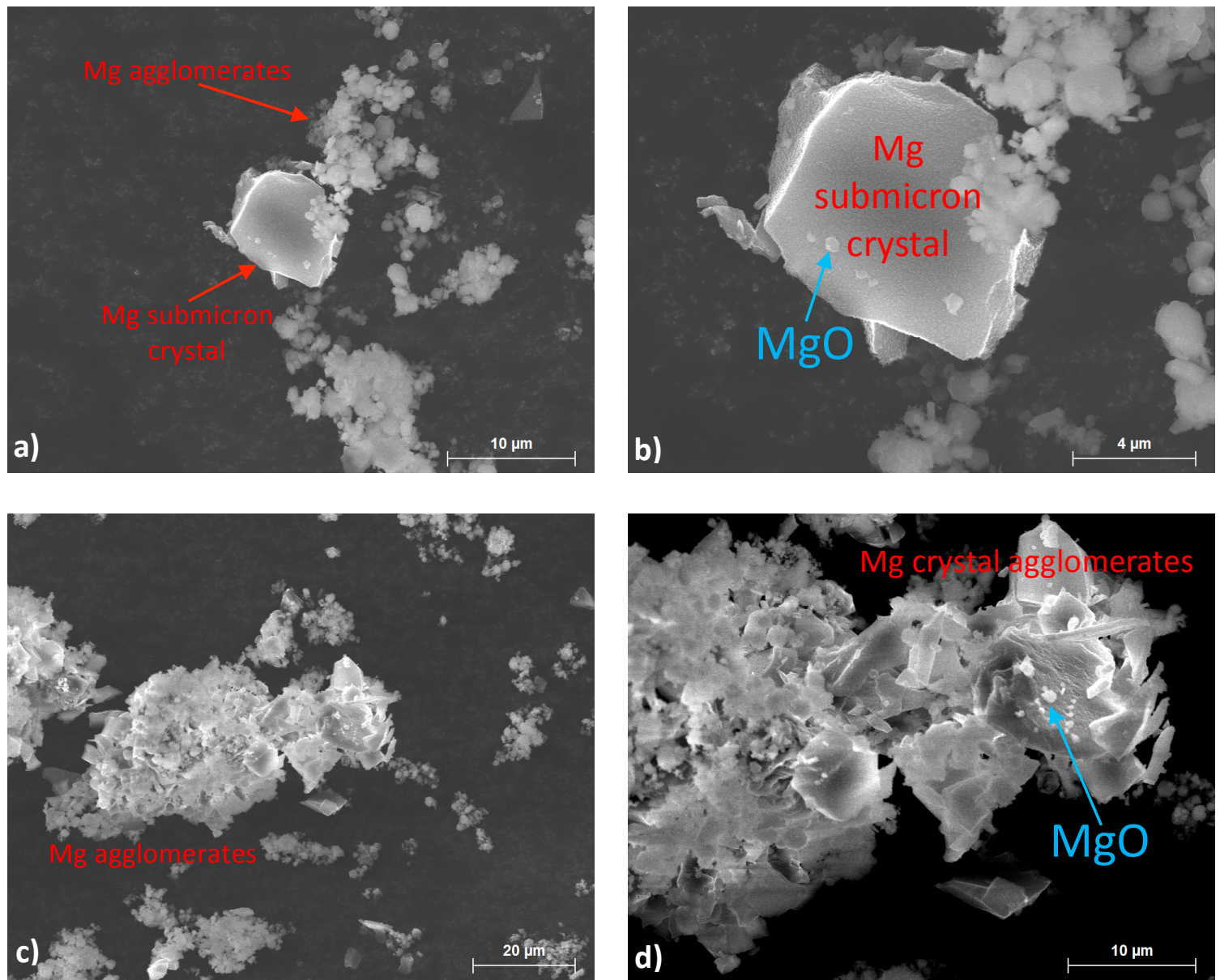

Figure 13. SEM images of the powders collected after the experiment A3 from a) and b) the filter, $\boldsymbol{c})$ and $\boldsymbol{d})$ the reactor walls. 


\subsection{Effect of metallic catalysts}

To investigate the effect of metal catalysts on the carbothermal reduction of magnesia, we performed two sets of experiments. In the first set, low activity chimney charcoal is used to compare the various catalysts $(\mathrm{Fe}, \mathrm{Ni}, \mathrm{Fe}-\mathrm{Ni})$ with different percentages. In the second set, the best catalyst is chosen and experiments are performed using high activity birch charcoal to probe the efficiency of the metal catalyst in presence of bentonite binder.

\section{5.a Using low activity charcoal}

During the following experiments, chimney charcoal is used to detect the effect of using iron and nickel catalysts on the carbothermal reduction of magnesia. Additionally, no bentonite binder is added to prevent the interference of the catalytic effect of bentonite with that of metallic catalysts. Table 3 presents the results of the $\mathrm{C} / \mathrm{MgO}$ pellet $(+5 \%$ starch) reduction using various percentages of metallic ( $\mathrm{Fe}$, Ni or $\mathrm{Fe}-\mathrm{Ni}$ ) catalysts during the progressive heating up to $60 \%$ shutter opening. Most of the produced powders are collected on the filter with a negligible amount deposited on the reactor walls (less than $1 \mathrm{mg}$ ). The first thing to notice is that using a metallic catalyst reduces critically the purity of the produced powders reaching about $76 \% \mathrm{Mg}$. This may be attributed to the formation of larger particles, observed by SEM, that are easier to oxide. The experiment with the $\mathrm{C} / \mathrm{MgO}$ pellet + 2\% Fe proved an outstanding performance overall the other experiment with a $\mathrm{Mg}$ yield of $38.5 \%$ compared to $20.7 \%$ without catalyst. In fact, when using $2 \% \mathrm{Fe}$, the quantity of the collected powder is around twice that without catalyst and the residual mass of pellet not reacted is much lower $(96 \mathrm{mg}$ for $\mathrm{C} / \mathrm{MgO}$ pellet $+2 \%$ Fe compared to around $130 \mathrm{mg}$ without catalyst). Those remaining consist mainly of magnesia with no carbon remains, as observed from the white color (Figure 14) and determined by semi-quantitative XRD where $94 \% \mathrm{MgO}$ value is found. This proves that the reduction is limited by the carbon content and that the 
metallic catalyst may accelerate the reaction and thus the carbon consumption without improving the yield. It has been noticed that the remains of all the pellets with metallic catalyst show an odd form (Figure 14 right) as if it was exploded internally compared to those without catalysts (Figure 14 left). Experiment with 5\% Fe and that with $10 \% \mathrm{Fe}-10 \%$ Ni give also a higher yield by around $10 \%$ than that without catalyst. However, for the following experiments where birch carbon is used, only $2 \% \mathrm{Fe}$ is considered to reduce the costs.

Table 3. Comparison of the carbothermal reduction of magnesia pellets using various metallic catalysts (Fe, $\mathrm{Ni}, \mathrm{Fe}-\mathrm{Ni})$ with different percentages in term of $\mathrm{Mg}$ yield and purity.

\begin{tabular}{|c|c|c|c|c|c|c|}
\hline & $\begin{array}{c}\mathrm{m}_{\text {pellet }} \\
(\mathrm{mg})\end{array}$ & $\begin{array}{l}\mathrm{T}_{\max } \\
(\mathrm{K})\end{array}$ & $\begin{array}{l}\mathrm{m}_{\text {collected }} \\
(\mathrm{mg})\end{array}$ & $\begin{array}{c}\text { Mg purity } \\
(\%)\end{array}$ & $\begin{array}{l}\text { Mg yield } \\
(\%)\end{array}$ & $\begin{array}{c}\mathrm{m}_{\text {residual }} \\
(\mathrm{mg})\end{array}$ \\
\hline $\mathrm{C} / \mathrm{MgO}$ pellet & 250.0 & 1695 & 22.3 & $97^{*}$ & 20.7 & 129.9 \\
\hline pellet $+2 \% \mathrm{Fe}$ & 253.0 & 2032 & 44.9 & $89 *$ & 38.5 & 96.0 \\
\hline pellet $+5 \% \mathrm{Fe}$ & 263.8 & 1733 & 35.8 & $87^{*}$ & 29.6 & 113.0 \\
\hline pellet $+10 \% \mathrm{Fe}$ & 253.7 & 1879 & 26.8 & 87 & 24.1 & 125.1 \\
\hline pellet $+20 \% \mathrm{Fe}$ & 255.5 & 1770 & 24.3 & $87 *$ & 23.7 & 120.2 \\
\hline pellet $+2 \% \mathrm{Ni}$ & 272.5 & 2200 & 35 & $82 *$ & 25.7 & 114.8 \\
\hline pellet $+5 \% \mathrm{Ni}$ & 251.3 & 1920 & 22.5 & $91^{*}$ & 20.4 & 129.7 \\
\hline pellet $+10 \% \mathrm{Ni}$ & 250.5 & 2151 & 19.6 & 83 & 17.1 & 132.3 \\
\hline pellet $+20 \% \mathrm{Ni}$ & 251.8 & 2129 & 22.8 & $83 *$ & 21.5 & 137.2 \\
\hline pellet $+2.5 \% \mathrm{Fe}+2.5 \% \mathrm{Ni}$ & 252.9 & 1946 & 31.7 & $76^{*}$ & 23.9 & 113.9 \\
\hline pellet $+5 \% \mathrm{Fe}+5 \% \mathrm{Ni}$ & 252.0 & 1956 & 24.0 & $81 *$ & 20.3 & 134.1 \\
\hline pellet $+10 \% \mathrm{Fe}+10 \% \mathrm{Ni}$ & 245.0 & 2063 & 32.0 & $81 *$ & 30.3 & 118.0 \\
\hline
\end{tabular}

\footnotetext{
*Determined through semi-quantitative XRD measurements. For other experiments, these values are admitted.
} 

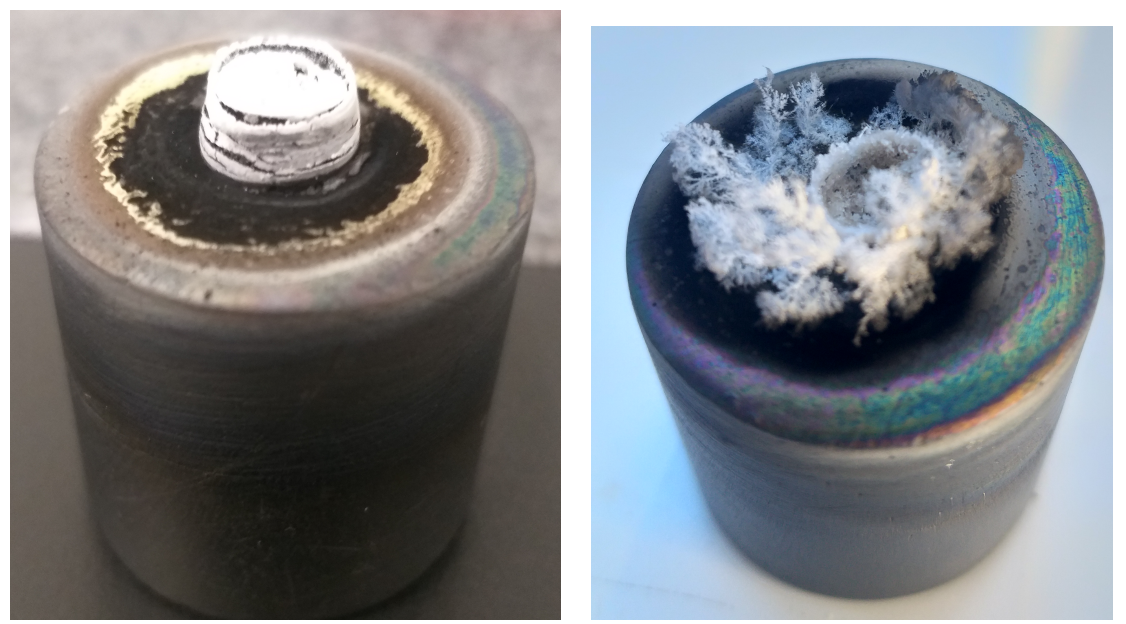

Figure 14. Photos of the remains of the $\mathrm{C} / \mathrm{MgO}$ pellet after the carbothermal reduction without (left) and with $2 \%$ Fe catalyst (right).

\section{5.b Using high activity charcoal}

The effect of the metallic catalyst $(2 \% \mathrm{Fe})$ on the carbothermal reduction of magnesia using high activity birch charcoal is probed by progressively increasing the temperature through opening the shutter gradually until it is fully open after $22 \mathrm{~min}$. Experiments are performed using starch and starch-bentonite binders to distinct the catalytic effect of iron from that of bentonite. Table 4 presents the results of the carbothermal reduction of $\mathrm{C} / \mathrm{MgO}$ pellets with $5 \%$ starch- $2 \%$ Fe or $5 \%$ starch $-5 \%$ bentonite- $2 \%$ Fe by comparing the weight of the produced powders collected on the filter and the reactor walls, the powders purity and consequently the total $\mathrm{Mg}$ yield. The reliability of the procedure is again confirmed by comparing experiments B1-B4 that showed similar results, except for B3 where a little lower yield (by around 10\%) is obtained as the DNI decreased during the reduction to $820 \mathrm{~W} / \mathrm{m}^{2}$. The catalytic-like behavior of the bentonite binder is once more confirmed as the yield increased from $68.4 \%$ when using $5 \%$ starch- $2 \%$ Fe (experiment B4) to around $77 \%$ when using 5\% starch-5\% bentonite- $2 \% \mathrm{Fe}$ (experiment B6). 
Table 4. Results of the carbothermal reduction of magnesia pellets with $2 \%$ Fe catalyst in term of $M g$ yield and purity of the powders collected on the filter and reactor walls.

\begin{tabular}{|c|c|c|c|c|c|c|c|c|c|}
\hline & $\begin{array}{l}\text { binder - } \\
\text { catalyst }\end{array}$ & $\begin{array}{c}\mathrm{m}_{\text {pellet }} \\
(\mathrm{mg})\end{array}$ & $\begin{array}{l}\mathrm{T}_{\max } \\
(\mathrm{K})\end{array}$ & $\begin{array}{l}\mathrm{CO}_{\max } \\
(\mathrm{ppm})\end{array}$ & $\begin{array}{c}\mathrm{m}_{\text {walls }} \\
(\mathrm{mg})\end{array}$ & $\% \mathrm{Mg}_{\text {walls }}$ & $\begin{array}{l}\mathrm{m}_{\text {filter }} \\
(\mathrm{mg})\end{array}$ & $\% \mathrm{Mg}_{\text {filter }}$ & $\begin{array}{l}\text { Total } \mathrm{Mg} \\
\text { yield }(\%)\end{array}$ \\
\hline $\mathrm{B} 1$ & $\begin{array}{c}5 \% \text { starch - } \\
2 \% \mathrm{Fe}\end{array}$ & 250 & 2478 & 3618 & 12.8 & $73 *$ & 66.1 & $90^{*}$ & 67.2 \\
\hline B2 & $\begin{array}{c}5 \% \text { starch - } \\
2 \% \mathrm{Fe}\end{array}$ & 252 & 2323 & 5503 & 12.8 & 73 & 63.9 & 90 & 64.5 \\
\hline B3 & $\begin{array}{c}5 \% \text { starch }- \\
2 \% \mathrm{Fe}\end{array}$ & 251 & 2440 & 4533 & 10.8 & 73 & 56.4 & 90 & $\begin{array}{c}57.0 \\
\text { (low DNI) }\end{array}$ \\
\hline B4 & $\begin{array}{c}5 \% \text { starch - } \\
2 \% \mathrm{Fe}\end{array}$ & 249 & 2392 & 5340 & 13.2 & 73 & 66.8 & 90 & 68.4 \\
\hline B5 & $\begin{array}{l}5 \% \text { starch - } \\
5 \% \text { bentonite } \\
-2 \% \mathrm{Fe}\end{array}$ & 211 & 2340 & 4787 & 17.6 & 38 & 59.8 & 91 & 73.9 \\
\hline B6 & $\begin{array}{l}5 \% \text { starch }- \\
5 \% \text { bentonite } \\
-2 \% \mathrm{Fe}\end{array}$ & 251 & 2263 & 5566 & 18.5 & $38 *$ & 75.5 & $91^{*}$ & 77.1 \\
\hline
\end{tabular}

*Determined through semi-quantitative XRD measurements. For other experiments, these values are admitted.

When comparing the following experiments with those performed in section 4.4 , we can conclude that using a metallic catalyst $(2 \% \mathrm{Fe})$ has a reverse negative effect on the reduction of magnesia as lower yields are obtained. The iron catalyst may accelerate the reaction at the beginning of the reduction thus decreasing the carbon content and increasing the magnesia sintering. For example, when comparing experiments using $\mathrm{C} / \mathrm{MgO}$ pellet $+5 \%$ starch with or without iron catalyst, we observe that the Mg yield decreased from $77.4 \%$ (experiment $\mathrm{A} 3$ ) to $68.4 \%$ (experiment B4). Similarly, when comparing experiments A6 and B6 (with 5\% starch-5\% bentonite), the $\mathrm{Mg}$ yield decreased by around $10 \%$ when the iron catalyst is added. Figure 15 confirms these conclusions by comparing the $\mathrm{CO}$ production overall the reaction time where the highest $\mathrm{CO}$ peak of about $7000 \mathrm{ppm}$ is reached at above $2000 \mathrm{~K}$ for experiment A10 (without Fe) compared to $5566 \mathrm{ppm}$ for experiment B6 (with Fe catalyst). Also, more $\mathrm{CO}_{2}$ is produced during experiment $\mathrm{B} 6$ compared to experiment $\mathrm{A} 10$, which asserts the previous statement that a lower $\mathrm{CO}_{2}$ emission is preferable. Moreover, comparing 
experiments A7 and B6, we find that the product purity decreased from $96 \%$ to $91 \%$ (on the filter) and 58 to $38 \%$ (on the reactor walls) when using an iron catalyst that confirms the conclusions stated in section 4.5.a.

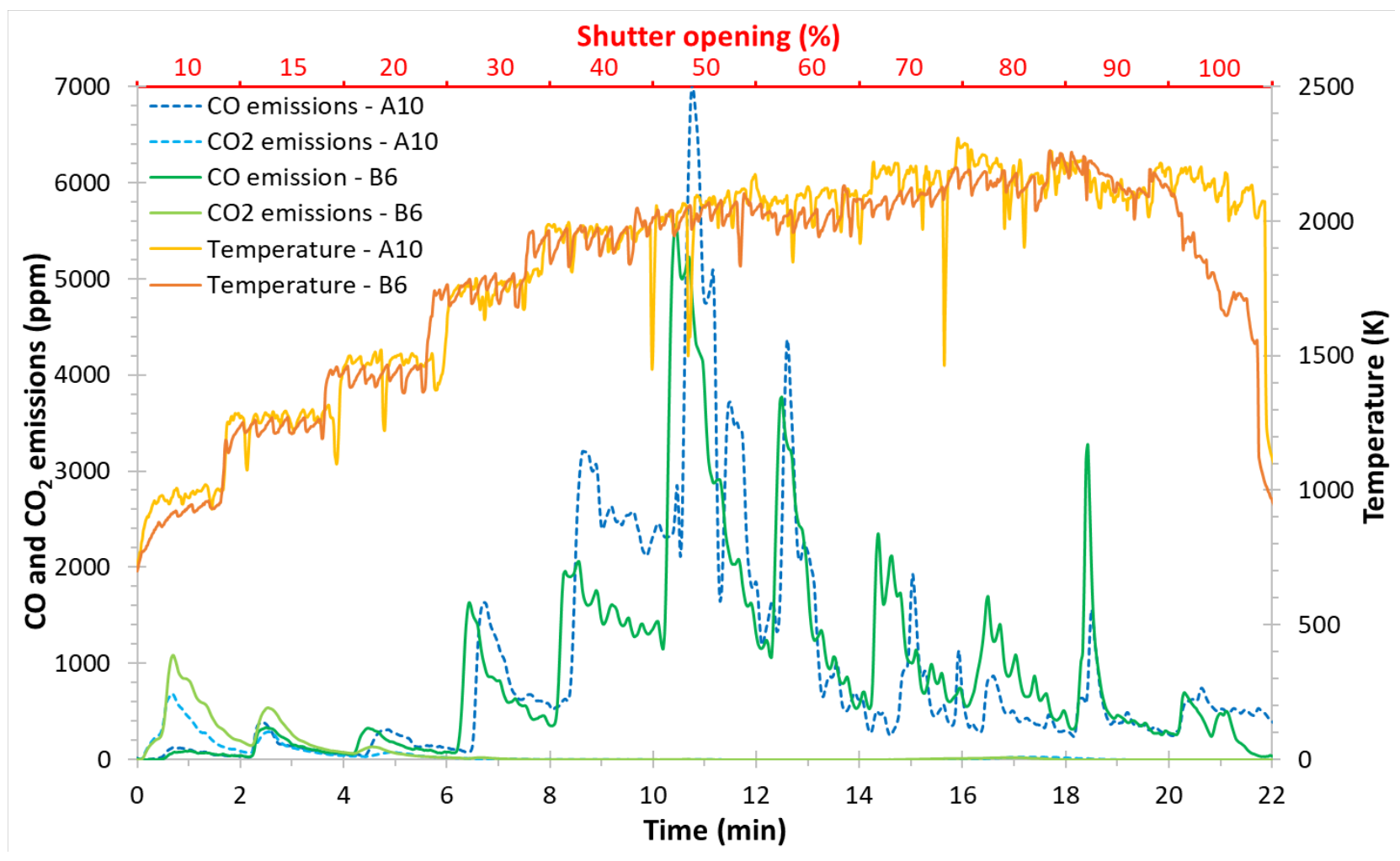

Figure 15. Temperature and gaseous emission ( $\mathrm{CO}$ and $\left.\mathrm{CO}_{2}\right)$ variation during the magnesia carbothermal reduction with (experiment B6) or without (experiment A10) iron catalyst.

\section{Conclusions}

The carbothermal reduction of magnesia using concentrated solar energy is an efficient process for magnesium recycling. This process provides sustainability, through reduction/combustion cycles, for the production of metal powders that are used as fuels in transportation. Herein, we are interested in this study to improve the performance of the process, through simulations and experiments, by investigating the flow circulation in the reactor, the effect of milling, and the catalytic effect of binders and metallic catalysts. Computational fluid dynamics simulations, performed using ASPEN, proved the beneficial 
effect of using a double argon entry from the upper and bottom parts of the reactor, which creates a swirl circulation allowing to purge the products from the pellet surface. Those results were confirmed by the experiments performed in the Sol@rmet reactor at around 830 Pa through a progressive increase of the temperature proving that the $\mathrm{Mg}$ yield increased from 52 to $68 \%$. Moreover, the mechanical milling of the magnesia powders with carbon will decrease the particle size and increase the surface area, thus improving the reduction and rising the $\mathrm{Mg}$ yield to around $85 \%$. Further, we compared the effect of adding a binder as polyvinyl alcohol, starch or starch-bentonite and of adding a metallic catalyst as $\mathrm{Fe}, \mathrm{Ni}$ or $\mathrm{Fe}-$ $\mathrm{Ni}$ at different percentages on the $\mathrm{Mg}$ yield and purity. Experiments proved that bentonite binder has a catalytic-like role more important than that of metallic catalysts. In fact, the iron catalyst would have an inverse negative effect on the reduction as it accelerates the reaction and the carbon consumption. Finally, we proved that when using birch charcoal with $5 \%$ starch-5\% bentonite binder, a Mg yield of $95 \%$ is reached with a similar product purity.

\section{Acknowledgments}

This study is funded under the STELLAR project by the "Agence Nationale de Recherche (ANR)" contract ANR-18-CE05-0040-02. This work was supported by the French "Investments for the future" program managed by the National Agency for Research, under contract ANR-10-EQPX-49-SOCRATE (Equipex SOCRATE). Authors would like to thank Eric Bêche, responsible of the characterization platform at PROMES-CNRS laboratory for XRD analysis.

\section{References}

Balomenos, E., Panias, D., Paspaliaris, I., 2012. Exergy Analysis of Metal Oxide Carbothemic Reduction under Vacuum - Sustainability prospects. Int. J. Thermodyn. 15, 141-148. https://doi.org/10.5541/ijot.376 
Ben-Zvi, R., 2013. Numerical simulation and experimental validation of a solar metal oxide reduction system under vacuum. Sol. Energy 98, 181-189. https://doi.org/10.1016/j.solener.2013.10.013

Bergthorson, J.M., Goroshin, S., Soo, M.J., Julien, P., Palecka, J., Frost, D.L., Jarvis, D.J., 2015. Direct combustion of recyclable metal fuels for zero-carbon heat and power. Appl. Energy 160, 368-382. https://doi.org/10.1016/j.apenergy.2015.09.037

Capellán-Pérez, I., Mediavilla, M., de Castro, C., Carpintero, Ó., Miguel, L.J., 2014. Fossil fuel depletion and socio-economic scenarios: An integrated approach. Energy 77, 641-666. https://doi.org/10.1016/j.energy.2014.09.063

Chubukov, B.A., Palumbo, A.W., Rowe, S.C., Hischier, I., Groehn, A.J., Weimer, A.W., 2016. Pressure dependent kinetics of magnesium oxide carbothermal reduction. Thermochim. Acta 636, 23-32. https://doi.org/10.1016/j.tca.2016.03.035

Chubukov, B.A., Palumbo, A.W., Rowe, S.C., Wallace, M.A., Sun, K.Y., Weimer, A.W., 2018. Design and Fabrication of Pellets for Magnesium Production by Carbothermal Reduction. Metall. Mater. Trans. B 49, 2209-2218. https://doi.org/10.1007/s11663-018-1309-5

Chubukov, B.A., Palumbo, A.W., Rowe, S.C., Wallace, M.A., Weimer, A.W., 2017. Enhancing the Rate of Magnesium Oxide Carbothermal Reduction by Catalysis, Milling, and Vacuum Operation. Ind. Eng. Chem. Res. 56, 13602-13609. https://doi.org/10.1021/acs.iecr.7b03175

Costandy, J., El Ghazal, N., Mohamed, M.T., Menon, A., Shilapuram, V., Ozalp, N., 2012. Effect of reactor geometry on the temperature distribution of hydrogen producing solar reactors. Int. J. Hydrog. Energy 37, 16581-16590. https://doi.org/10.1016/j.ijhydene.2012.02.193

Dussud, F.X., Joassard, I., Wong, F., Duvernoy, J., Morel, R., 2015. Key climate figures of France and the world, Edition 2016. Presented at the UN climate change conference, Paris (presented in French: Chiffres clés du climat France et Monde).

Fruehan, R.J., Martonik, L.J., 1976. The Rate of reduction of MgO by carbon. Metall. Trans. B 7, 537542. https://doi.org/10.1007/BF02698585

Griessacher, T., Antrekowitsch, J., Steinlechner, S., 2012. Charcoal from agricultural residues as alternative reducing agent in metal recycling. Biomass Bioenergy 39, 139-146. https://doi.org/10.1016/j.biombioe.2011.12.043

Hoel, M., Kverndokk, S., 1996. Depletion of fossil fuels and the impacts of global warming. Resour. Energy Econ. 18, 115-136. https://doi.org/10.1016/0928-7655(96)00005-X

Inc Ansys., 2013. Ansys CFX-Solver Modeling Guide (15.0 version).

Laboureur, P., Lomba, R., Halter, F., Chauveau, C., Dumand, C., 2018. The use of solid combustible in thermal engines. Presented at the $9^{\text {th }}$ edition of the Francophone colloquium on Energy, Environment, Economy and Thermodynamics (COFRET'18), https://hal.archivesouvertes.fr/hal-01860128, Strasbourg (presented in French at the $9^{\text {ème }}$ édition du COlloque FRancophone en Energie, Environnement, Economie et Thermodynamique: Utilisation de la combustion solide dans les machines thermiques).

Laraqui, D., Allgaier, O., Schönnenbeck, C., Leyssens, G., Brilhac, J.-F., Lomba, R., Dumand, C., Guézet, O., 2019. Experimental study of a confined premixed metal combustor: Metal flame stabilization dynamics and nitrogen oxides production. Proc. Combust. Inst. 37, 3175-3184. https://doi.org/10.1016/j.proci.2018.07.018

Laraqui, D., Leyssens, G., Schonnenbeck, C., Allgaier, O., Lomba, R., Dumand, C., Brilhac, J.-F., 2020. Heat recovery and metal oxide particles trapping in a power generation system using a swirlstabilized metal-air burner. Appl. Energy 264, 114691. https://doi.org/10.1016/j.apenergy.2020.114691

Lomba, R., Bernard, S., Gillard, P., Mounaïm-Rousselle, C., Halter, F., Chauveau, C., Tahtouh, T., Guézet, O., 2016. Comparison of Combustion Characteristics of Magnesium and Aluminum Powders. Combust. Sci. Technol. 188, 1857-1877. https://doi.org/10.1080/00102202.2016.1211871 
Lomba, R., Halter, F., Chauveau, C., Bernard, S., Gillard, P., Mounaim-Rousselle, C., Tahtouh, T., Guezet, O., 2015. Experimental characterization of combustion regimes for micron-sized aluminum powders, in: $53^{\text {rd }}$ AIAA Aerospace Sciences Meeting. Presented at the $53^{\text {rd }}$ AIAA Aerospace Sciences Meeting, American Institute of Aeronautics and Astronautics, Kissimmee, Florida. https://doi.org/10.2514/6.2015-0925

Murray, J., Steinfeld, A., Fletcher, E., 1995. Metals, nitrides, and carbides via solar carbothermal reduction of metal oxides. Energy 20, 695-704. https://doi.org/10.1016/03605442(95)00032-C

Nusheh, M., Yoozbashizadeh, H., Askari, M., Kuwata, N., Kawamura, J., Kano, J., Saito, F., Kobatake, H., Fukuyama, H., 2010. Effect of Mechanical Milling on Carbothermic Reduction of Magnesia. ISIJ Int. 50, 668-672. https://doi.org/10.2355/isijinternational.50.668

Puig, J., Balat-Pichelin, M., 2018. Experimental carbothermal reduction of MgO at low pressure using concentrated solar energy. J. Min. Metall. Sect. B Metall. 54, 39-50. https://doi.org/10.2298/JMMB170215048P

Puig, J., Balat-Pichelin, M., 2017. Production of Mg and Al using concentrated solar energy for future fuel applications. Presented at the Proceedings of EMC 2017.

Puig, J., Balat-Pichelin, M., 2016. Production of metallic nanopowders (Mg, Al) by solar carbothermal reduction of their oxides at low pressure. J. Magnes. Alloys 4, 140-150. https://doi.org/10.1016/j.jma.2016.05.003

Rongti, L., Wei, P., Sano, M., Li, J., 2003. Catalytic reduction of magnesia by carbon. Thermochim. Acta 398, 265-267. https://doi.org/10.1016/S0040-6031(02)00324-6

Rongti, L., Wei, P., Sano, M., Li, J., 2002. Kinetics of reduction of magnesia with carbon. Thermochim. Acta 390, 145-151. https://doi.org/10.1016/S0040-6031(02)00128-4

Steinfeld, A., Palumbo, R., 2003. Solar Thermochemical Process Technology, in: Encyclopedia of Physical Science and Technology. Elsevier, pp. 237-256. https://doi.org/10.1016/B0-12227410-5/00698-0

Tian, Y., Qu, T., Yang, B., Dai, Y.-N., Xu, B.-Q., Geng, S., 2012. Behavior Analysis of $\mathrm{CaF}_{2}$ in Magnesia Carbothermic Reduction Process in Vacuum. Metall. Mater. Trans. B 43, 657-661. https://doi.org/10.1007/s11663-011-9622-2

Touloukian, Y.S., Dewitt, D.P. (Eds.), 1970. Thermal radiative properties: metallic elements and alloys, in: Thermophysical Properties of Matter: The TPRC Data Series; a Comprehensive Compilation of Data. Vol. 7 Part 2. IFI/Plenum, New York, NY.

Vishnevetsky, I., 2016. Solar Thermal Reduction of Metal Oxides as a Promising Way of Converting CSP Into Clean Electricity on Demand, in: Proceedings of the ISES Solar World Congress 2015. Presented at the ISES Solar World Congress 2015, International Solar Energy Society, Daegu, Korea, pp. 1-12. https://doi.org/10.18086/swc.2015.04.23

Vishnevetsky, I., Epstein, M., 2015. Solar carbothermic reduction of alumina, magnesia and boria under vacuum. Sol. Energy 111, 236-251. https://doi.org/10.1016/j.solener.2014.10.039

Vishnevetsky, I., Epstein, M., Rubin, R., 2014. Solar Carboreduction of Alumina under Vacuum. Energy Procedia 49, 2059-2069. https://doi.org/10.1016/j.egypro.2014.03.218

Xiong, N., Tian, Y., Yang, B., Xu, B., Dai, T., Dai, Y., 2019. Results of recent investigations of magnesia carbothermal reduction in vacuum. Vacuum 160, 213-225. https://doi.org/10.1016/j.vacuum.2018.11.007 